\title{
From autopoiesis to neurophenomenology: Francisco Varela's exploration of the biophysics of being
}

\author{
DAVID RUDRAUF, ANTOINE LUTZ, DIEGO COSMELLI, JEAN-PHILIPPE LACHAUX, \\ and MICHEL LE VAN QUYEN
}

Laboratoire de Neurosciences Cognitives et Imagerie Cérébrale, CNRS UPR 640,Paris, France

\begin{abstract}
This paper reviews in detail Francisco Varela's work on subjectivity and consciousness in the biological sciences. His original approach to this "hard problem" presents a subjectivity that is radically intertwined with its biological and physical roots. It must be understood within the framework of his theory of a concrete, embodied dynamics, grounded in his general theory of autonomous systems. Through concepts and paradigms such as biological autonomy, embodiment and neurophenomenology, the article explores the multiple levels of circular causality assumed by Varela to play a fundamental role in the emergence of human experience. The concept of biological autonomy provides the necessary and sufficient conditions for characterizing biological life and identity as an emergent and circular self-producing process. Embodiment provides a systemic and dynamical framework for understanding how a cognitive self - a mind - can arise in an organism in the midst of its operational cycles of internal regulation and ongoing sensorimotor coupling. Global subjective properties can emerge at different levels from the interactions of components and can reciprocally constrain local processes through an ongoing, recursive morphodynamics. Neurophenomenology is a supplementary step in the study of consciousness. Through a rigorous method, it advocates the careful examination of experience with first-person methodologies. It attempts to create heuristic mutual constraints between biophysical data and data produced by accounts of subjective experience. The aim is to explicitly ground the active and disciplined insight the subject has about his/her experience in a biophysical emergent process. Finally, we discuss Varela's essential contribution to our understanding of the generation of consciousness in the framework of what we call his "biophysics of being."
\end{abstract}

Key terms: Autonomous systems; Brain dynamics, Consciousness, Embodiment, Francisco Varela, Neurophenomenology.

\section{INTRODUCTION}

In this paper we will review Francisco Varela's ideas about what is now often called the "hard problem" (Chalmers, 1996): the issue of the relationships between our subjective experience and our objective bio-physical embodiment.

Francisco Varela liked to introduce himself by saying: "I' $m$ a biologist who has been interested in the biological roots of cognitive phenomena" (Varela, 1990). From this standpoint, he investigated the biological basis of subjectivity and conscious experience throughout his life as a researcher. He did so in a very original way, illuminating this fundamental issue with deep and fascinating insights.
In the last years of his life, he proposed a scientific research program, which he called neurophenomenology (Varela, 1996), that aimed to address the problem pragmatically. This program has already produced interesting results (Lutz et al, 2002) and is currently being conducted by colleagues from his French Brain Dynamics team, including the authors of this paper. With more than 180 published articles and 10 books (not to mention the many books he edited), Francisco's work extends into many scientific fields: cybernetics, neurophysiology, theoretical biology, mathematics, immunology, epistemology, neuropathology (epileptology), brain imaging and brain dynamics. 
Francisco Varela was a mentor to all of the present authors: one year after his premature death, this article serves both as homage and as an occasion to share one possible synthesis of his work with the scientific community. One of its goals is to disclose the coherence of his thinking throughout his career, situating his later and final views on the biology and phenomenology of consciousness within the framework of his general theory of autonomous systems. This theory, developed early on, is essential for a full understanding of what he meant by "embodied mind" (Varela et al, 1991; Thompson and Varela, 2001).

Although this article is presented as a synthesis, we have chosen to include a large corpus of quotes and references in order to provide the reader with concrete points of access to these abstract and complex ideas. We have used a system of notes so as not to interrupt the flow of the text.

The framework sketched here is necessarily partial in relation to the richness and multiplicity of Francisco Varela's thought, which includes not only reflections on theoretical biology, immunology, neuroscience, phenomenology and the epistemology of science, but also on ethics and spirituality, domains of profound personal commitment for him.

Finally, while the authors obviously agree on the views and material presented here, the interpretations and emphasis placed on different aspects of Francisco's work by each one of us clearly varies. Given the richness and diversity of his thought, we cannot claim to have exhausted all possible points of view in this synthesis; indeed, to attempt to do so would only limit the possibilities of our own personal explorations of his deeply insightful work.

\section{The thematic landscape}

Through more than thirty years of research Francisco searched for an account of cognition. Some periods of particular interest can be distinguished: the years from 1968 to 1986 were marked by his work both on the neurophysiology of vision and on cybernetics, first with Torsten Wiesel at Harvard and later with Humberto Maturana at the University of Chile, (reflections on brain organization can already be seen here); from 1986 to 1995 he was particularly interested in self-organization in immune networks; finally, from 1995 until his death in May 2001, he worked on brain dynamics, anticipation of epileptic seizures and neurophenomenology with his French brain dynamics group in the Cognitive Neuroscience and Brain Imaging Laboratory in Paris.

Yet this arbitrary division into historical periods should not mask the continuity of his thinking: as early as 1971 he devoted an article to the issue of self-consciousness (Varela, 1971) while in 1997 he was still writing about autopoiesis and autonomy (Thompson and Varela, 1999).

For Francisco, theory was a crucial complement to experimentation in scientific work. Almost two thirds of his articles, book chapters and reviews are theoretical: about a quarter are experimental papers, principally produced during the first and last periods of his career; the rest are methodological papers, mainly written during the last period of his life, in which Varela addressed large-scale synchronies and non-linear analysis of brainwaves, including works on seizure anticipation.

In the following paper, while many of the Francisco's views might appear to be very speculative, they are so in a heuristic way: we hope they will be received as the fundamental contribution we believe them to be.

Setting the stage: experience as explanandum

It is a major challenge for contemporary naturalistic science to explain the existence and functioning of consciousness on a subjective, experiential level as well as in terms of its putative causal efficiency (Petitot et al, 1999). The recent development of brain imaging techniques (such as fMRI, PET, MEEG/EEG) and progress made in signal analysis for 
characterising fast dynamical interactions (cf. Tootell et al, 1998; Lachaux et al, 1999; Friston, 2002), which allow the study of the human brain during cognitive tasks, have provided an essential experimental framework for research into consciousness.

Nevertheless, in spite of an array of theoretical propositions (Edelman, 1989, 2001; Gray 1995; Block, 1996 ; Tononi and Edelman,1998a, 1998b; Crick and Koch, 1998; Damasio, 1994, 1995, 1999, 2000, 2001; Parvizi and Damasio, 2001; Engel and Singer, 2001; Logothetis 1998a; Dehaene and Naccache 2001; Varela et al 1991; Varela, 1999a; Roy et al, 1999; Thompson and Varela 2001; Zeman, 2001), as well as encouraging experimental results on the neural correlates of consciousness (Lane et al, 1998; Logothetis 1998b; Rodriguez et al, 1999; Srinivasan et al, 1999; Damasio et al, 2000; Beauregard et al, 2001; Lutz et al,2002), the scientific community is still grappling with what is known as the "explanatory gap" (Levine, 1983): the relationships between an individual's physical system and his subjective properties remain obscure.

Computationalist, functionalist or neuroreductionist approaches generally lead to a paradoxical eliminativism, i.e. the elimination of consciousness as the domain of our subjective experience during the very process of explanation. No evidence about the relation between the objective and subjective realms can be provided if the initial explanandum itself (that which has to be explained), has been banished as a valid object of study! In the explanation, phenomenal properties of consciousness as such must appear (Varela, 1976; Varela, 1996; Roy et al, 1999).

Contrary to eliminativism, it is well known that Francisco's position was situated squarely in the context of what he saw as the irreducible nature of conscious experience.

As early as 1976 (Varela, 1976), he called for a science of the "sense of self," of "direct knowledge"1. He sought a science of mind embodiment (Varela et al, 1991) that incorporates "experience," "being there" (Varela, 1999c), "sentience" and "the feeling of being alive" (Thompson and Varela, 2001). He addressed the need for a methodology to explore this realm, "an experiential neuroscience" (Varela, 1999b) at the concrete roots of the emergence of consciousness. Varela posed the problem as follows: "on the one hand we need to address our condition as bodily processes; on the other hand we are also an existence which is already there, a Dasein, constituted as an identity, and which cannot leap out and take a disembodied look at how it got to be there" (Varela, 1991). For Francisco, cognition always takes place in the context of "feeling consciousness and intuition" (Varela, 1976).

"Experience" or "phenomenal experience" (Varela, 1996) is that part of our cognition that we access from a subjective point of view; it is the realm of consciousness. "Mind," on the other hand, embraces the more general domain of cognition, which includes conscious and unconscious phenomena while always being rooted in a self. Indeed, our intuitive apprehension of mind shows it to be fundamentally related to subjectivity and consciousness: A mind is always someone's mind, my mind; thus, the issue of the mind cannot be seen to be independent from that of the self. In Francisco's words: "Here, by 'mind' I mean anything that has to do with mentality, with cognition and ultimately with experience" (Varela, 1999b).

\section{The Nagel Effect}

In Nagel's famous article, What is it like to be a bat?, to which Francisco often referred (1974) the author framed the issue by stating that "fundamentally an organism has conscious mental states if and only if there is something that it is like to be that

\footnotetext{
1 In 1976 Francisco (Varela, 1976) already deplores "that description of other minds (generally addressed in term of computation, neurological net and logical discourses) leaves a residue, my mind, including the "being," the "sense of self," a "direct knowledge," "experience" : "as long as there is such a remnant [...] the Mind-Body relation is still a problem."
} 
organism - something it is like for the organism." For Nagel this "effect" corresponds to the "subjective character of experience," which is related to a "point of view," constituting the "essence of the internal world." Pithily, he observes that "if mental processes are indeed physical processes, then there is something it is like, intrinsically, to undergo certain physical processes." We will refer to this hypothetical mental effect of having physical processes as the Nagel Effect.

Within such a framework we must wonder, as Nagel suggests, what "objectivity" can tell us about subjective experience, how an objective process can have a subjective nature and, reciprocally, how subjective experience can have an objective nature.

According to the physics model, "objectivity" accounts for observable properties in the World, by describing them as spatial-temporal interactions between spatial-temporal elements defined as structures or dimensions in a state space with laws of evolution. Objectivity is the realm of the phenomenology of objects, processes, trajectories, force, field, attraction, repulsion, acceleration, mass, energy, etc. The crucial question is how such modes of description can provide us with deep insights about the "origin" of our subjective experience. ${ }^{2}$

According to Francisco, the search for the origin of this Nagel Effect of subjective experience must be grounded in the notion of a "radical embodiment," that is, in the concrete situated phenomenology of our coping as a biophysical system (Varela et al, 1991; Thompson and Varela, 2001).

Embodiment is a key, if complex, concept. This article will illuminate precisely what
Francisco meant by embodiment or embodied mind. References to the notion of embodiment always include the notion of mind; in humans, it cannot be separated from either the notion of mind or that of self. In Francisco's view, embodiment is our departure point as living beings, a given that we must characterize, but also the explanans, i.e. the domain of explanation for a future science of being. Embodiment is fundamentally related to what he called the natural history of circularity (Varela, 1988a). Throughout this article the notion of circularity and its precise phenomenology will be omnipresent.

As will become apparent in the following pages, his theory of embodiment continuously moves between the pursuit of an operational, concrete description of biophysical processes and the choice of very abstract and general tools to build explanations or fill out insights (Varela, 1979). Yet these abstract or general concepts were always shaped to fit as closely as possible the model or nature of the system's mechanisms. Francisco studied the natural fact of embodiment simultaneously from the perspectives of a biologist, a cybernetician and a neuroscientist, often using tools and systemic descriptions based on non-linear mathematical physics ${ }^{3}$. His approach motivated the reference to a biophysics of being ${ }^{4}$ in the title of this article.

At the same time, Francisco's conceptions are all grounded in a phenomenological approach to subjectivity as well as to the organism itself. In Francisco's theoretical developments, ${ }^{5}$ the embodiment of mindwhether approached from the first- or thirdperson point of view-always has the character of a descriptive phenomenology.

\footnotetext{
${ }^{2}$ In this sense objectivity is simply a phenomenology, a description of behaviors of systems in general. As such, it obviously depends on an observer. But, for the moment let us avoid the realism/idealism debate, by saying that this does not really matter! Even if "objective" descriptions are mental constructions, let us just work within their internal logic without wondering if they correspond to a reality per se. As in other realms of science, the criteria for "understanding" should only be the heuristic value and conceptual generative power of such an approach without needing to refer to the issue of its metaphysical ontology.

3 The biological spontaneity and complex behaviors of living beings, their intrinsic dynamic character, drove Francisco to call for "a brownian science," a "rigorous theory of vagueness" adapted to biological systems (Varela, 1981).

${ }^{4}$ Far from having any exclusively molecularist connotations, here the notion of biophysics can be understood as the scientific horizon of an integrative biophysics yet to come.

${ }^{5}$ In The specious present (Varela, 1999a), Francisco promoted naturalizing phenomenology as well as "phenomenologizing”" neuroscience.
} 
This paper is an attempt to highlight the logic that guided the greater part of Francisco's work, starting from his general principles of "living systems" as a necessary prelude to the understanding of human subjectivity. Our approach to Francisco's theory follows a 'constructivist' path: beginning with the theory of autopoiesis and autonomy, we move on to examine how Francisco frames embodiment theoretically, and end with neurophenomenology. Although our objective is not to look at the concepts historically, the order of this presentation coincides generally with the historical order of Francisco's conceptual developments.

THE FRAMEWORK: THE CONDITION OF BEING AN AUTONOMOUS SYSTEM

Our point of departure as embodied beings is situated in a general framework that concerns all living systems: that of autonomy. ${ }^{6}$ In this section, we will present Francisco's thought on our fundamental organization as living beings, and the corresponding theoretical object he constructed: the autonomous system.

\section{Life as a " bringing forth" of identity}

"What are the biological roots of individuality?"(Varela, 1987) The fundamental feature that Humberto Maturana and Francisco identified in their search for what is common to all living beings (that which makes us recognize them as belonging to the same class despite their diversity), was the evidence of a unitary nature, a coherent wholeness, an autonomy that is "brought forth" by the system itself (Maturana and Varela, 1973; Varela et al, 1974; Maturana and Varela, 1980). There is a "capacity of living systems to maintain their identity in spite of the fluctuations which affect them" (Varela, 1979; Maturana and Varela, 1973; Varela et al, 1974). This identity is actively resistant to all the natural forces and tendencies, such as the increase of entropy, that tend to annihilate it. What is indeed fascinating about living beings is that they assert their identity from within, thus opening up the possibility of observing them as distinct units in their domain of operation. The living being is a process, that of "being autonomous" (Varela, 1977a). Therefore, it is not Reproduction or Evolution or any list of properties that primordially characterizes life, but rather individual organization that allows for autonomy (Varela, 1984a). For instance we can conceive of the existence of such an organization without ability of Reproduction and Evolution, but the reciprocal is not true.

As an autonomous individuality, a living system does indeed present itself to observers with "wholeness," as a "systemwhole," a "total, closed, complete, full, stable, self-contained system" (Varela, 1976). As a whole, it behaves as a dynamical system exhibiting continuous structural changes but with organizational invariance. This organizationally invariant process defines the system's identity (Varela, 1984a): "the domain of deformations that the system can be submitted to without losing its identity (i.e. and still maintain its organization) is the domain of transformations where it exists as a unity" (Varela, 1979).

From a cybernetic perspective Francisco conceived this wholeness as the result of a co-dependency of parts in an ongoing process: "A whole is here a set of simultaneous interactions of parts (components, nodes, sub-systems) which exhibit stability as a totality. The parts are the carriers of particular interactions which we can chop out from the whole and consider their participation in various sequential processes that constitute the

\footnotetext{
${ }^{6}$ In this section we introduce Francisco's concepts of autonomy and autopoiesis. As we chose to focus on the embodiment of mind and consciousness in this article, we will consider these concepts from the perspective of embodied living beings, which are "autopoietic systems in the physical space" (Varela, 1976), and particularly in the context of animals, as this is precisely our own condition of being. But we must note that in Francisco's theory "autonomy" is " a general phenomenon applicable in other spaces of interaction" such as ecosystems, artificial intelligence and artificial life, social sciences, linguistics, economics and so on. In the same way autopoiesis can apply in abstract space.
} 
whole. The whole re-emerges when we see the resulting total stability (i.e. the fixed point of the limit process)" (Varela, 1976). Thus, it is more than a question of specific chemical components (carbon hydrates, proteins, lipids, nucleic acids, etc.), but is fundamentally one of "the relations which the components must satisfy in order to constitute a living system" (Varela, 1979).

Within this framework it must be noticed that Francisco's approach was radically mechanistic: "our approach will be mechanistic. We won't appeal to any forces or principles not belonging to the universe of physics [...] We adopt in fact the basic principles of the Cybernetics and the Theory of systems. What is just the essence of the modern mechanism. Living systems are "machines"' (Varela, 1979). Thus, for Francisco, living beings were "mechanistic (dynamical) systems defined by their organization" (Varela, 1981).

Starting from these considerations, Francisco and Humberto Maturana proposed a general but powerful biophysical mechanism, foundational to what Varela called the "bio-logic" (Varela, 1991).

Contrary to the usual way a machine functions, with a product that is different from the machine itself, in the case of living machines self-production is the fundamental defining feature of the autonomy of the organism (Maturana and Varela, 1973). Thus, in the particular case of living organisms, the mechanism of autonomy was baptized autopoiesis or selfproduction: "An autopoietic system is organized (defined as a unity) as a network of processes of production (transformation and destruction) of components that produces the components that: 1) through their interactions and transformations continuously regenerate and realize the network of processes (relations) that produce them; and 2) constitute it (the machine) as a concrete unity in the space in which they exist by specifying the topological domain of its realization as such a network" (Varela, 1979).

In such a process (Fig 1) there is a mutual specification or definition of the internal, chemical transformations and of the physical boundaries (Varela, 1988b). Identity emerges and persists within the bounded system through a continuous circular or recurrent process. Specific organizational relations (like the ensemble of biochemical pathways of the cell and its membranes), bounding the metabolism and the physiology of the system, are continuously regenerating through the internal production of their substratum components (cell organelles and structures, molecules controlling the metabolism) in

\section{matter, energy flow}

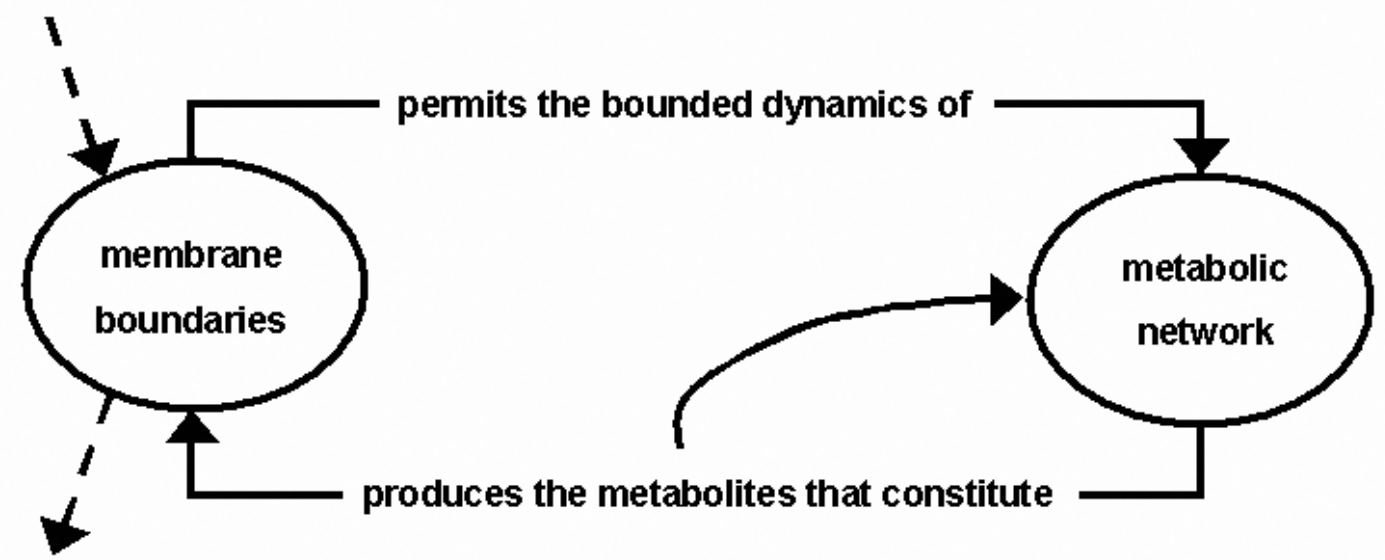

FIGURE 1 - The autopoietic machine: a circular causality.

The autopoietic organization is defined as a unit by a network of production of components (chemical reactions) which (i) participate recursively in the same network of production of components (chemical reactions) that produced them, and (ii) carry out the network of production as a unit in the space in which the components exist. 
the correct functional, dynamical and spatial distribution. In other words, the system continuously produces itself through the production of its own components in the topological distribution that the ongoing global process constrains, and that the components require to maintain the relations that define them. Living systems "transform matter in themselves in such a way that their organization is the product of their operation" (Varela, 1979).

Within such a self-referential framew ork, the "origin of life" is conceived as the transition from a chemical environment to a self-produced identity (Dupuy and Varela, 1991). The most paradigmatic case exemplifying this mechanism is that of cell autonomy, but it applies to all living systems. This is valid also for superior organisms whose internal self-producing mechanism lies in integrated, recurrent, internal, metabolic and physiological relationships, with increasingly complex behaviors and functional dependencies.

As generative of living autonomous systems, autopoiesis appeared to Francisco as the common, specific feature, the uniqueness, of life: autopoiesis is "the mechanism which endows living systems with the property of being autonomous; autopoiesis is an explication of the autonomy of the living" (Varela, 1981). It is the biophysical origin of individuality: "It is autopoiesis which defines the cell as a unity endowed with an individuality" (Varela, 1979). Furthermore, autopoiesis is a generative concept: "We claim that the notion of autopoiesis is necessary and sufficient to define the organization of the living being" (Maturana and Varela, 1973). To Francisco's mind, this far from equilibrium process lives: "If a physical system is autopoietic, it is living." Described as a mechanism, autopoiesis makes the link between physics and biology: "The phenomenology of living systems is then the mechanicist phenomenology of the physical autopoietic machines [...] with purely mechanicist notions, true for every mechanicist phenomenon in any space, one can explain completely this organization and its origin." (Varela, 1979) ${ }^{7}$

\section{Organizational closure: the general logic of embodiment}

The fundamental salient feature of this framework of autonomy is the circular, closed, self-referential characteristic of the organization of the living system, which creates a minimal distinction between an interior and an exterior, and guarantees the continuous dynamical, mechanic generation of the stable "internal coherence" of an autonomous system (Varela and Goguen, 1977). To delineate this circular organization and causality at work in the network of co-dependencies of such systems, Francisco proposed, within the framework of what he called a "systemcentered" logic, the general concept of organizational closure or operational closure.

"Closure" is the circular mechanism defining the class of self-organizing systems in general. ${ }^{8}$ Autopoietic systems are "a particular case of a larger class or organization that can be called organizationally closed" (Varela, 1979).

For Francisco this concept was essential for an understanding of the condition of a living system: "in order to study life and cognition, we need to explore the almost entirely unexplored land of autonomousclosure machines, clearly distinct from the classical Cartesian input-machines" (Varela, 1984a).

Closure is a response to the attempt 1) to formalize and to characterize the mechanism of "autonomy in general" as a self-organizing behavior and 2) to specify

\footnotetext{
${ }^{7}$ Francisco summarized the features characterizing organisms within this framework. Proposition I: Organisms are fundamentally a process of constitution of an identity. Proposition II: The organism's emergent identity gives, logically and mechanistically, the point of reference for a domain of interactions (Varela, 1997a).

${ }^{8}$ From a topological point of view, he defined closure as follows: "A domain $\mathrm{K}$ has closure if all operations defined in it remain within the same domain. The operation of a system has therefore closure, if the results of its action remain within the system itself." (Bourgine and Varela, 1992)
} 
the circular organization or mechanism of a given autonomous system as it gives rise to its specific identity: closure accounts not only for the "uniqueness" of Life but also for its "diversity" (Varela, 1981). The observable specificity of living beings indicates that there is species-specific organizational closure. Each system has its own way of being operationally closed. Organizational closure specifies the domain of interaction of the system with its surroundings, conditioning its possible ways of coupling with the environment. In higher organisms, the meshwork of codependencies includes the different physiological systems (cardio-vascular, respiratory, nervous, immune, etc.), and their sub-systems. The components involved and the kind of interactions to be considered depend upon the type of autonomous systems to be considered at (cells, organisms, animal populations, ecological systems).

Moreover, there are two aspects of closure: organizational, which defines the possible interactions in a "static" circular framework, and operational, i.e. the recurrent dynamics that closure elicits. ${ }^{9}$ As such, the concept of closure aims to introduce a "universal mechanism for stabilization." Identity is always identity in time, and exists in relation to an environment with perturbations that must be compensated for. This process of recurrent stabilization, involving internal circular processes with matter and energy flux, is at the core of the dynamical persistence of the autonomy and wholeness of the system. As a whole, the system exists and subsists only insofar as it is organizationally closed. When a system no longer has organizational closure, it is no longer in its domain of viability, and therefore dies.

It is essential to understand that the idea of closure does not contradict that of openness. Closure doesn't mean a closed system. We are looking at far from equilibrium systems, with an exchange of matter and energy with their surroundings (Varela , 1977a). The core of circular causality is coupled with the system's trophic and adaptive dependence on its environment. Francisco always emphasized that a system is "not separable from its interaction domains" (Varela, 1980a).

Francisco's thesis maintains that every system-whole is organizationally closed: "The wholeness of a system is embodied in its organizational closure. The whole is not the sum of its parts; it is the organizational closure of its parts" (Varela and Goguen, 1977).

This last point must be kept in mind in the following paragraphs. It can be seen as the fundamental feature and the first theoretical definition of embodiment.

\section{Intuiting the dynamic core}

The adaptations and highly complex behaviors of animals sometimes make them appear as if they had their own 'project,' as if they had an intrinsic intentionality. However, notions such as those of 'goal' and 'purpose' come from a realm of discourse proper to observers describing and somehow summarizing the behavior of a system. Since they overlook the effective

\footnotetext{
${ }^{9}$ The system's stability is dynamic. It centers on a huge internal movement, a perpetual flow. Therefore, autonomy is the result of the set of possible internal transformations or endomorphisms $\left[\mathrm{S}^{\mathrm{n}} \Rightarrow \mathrm{S}^{\mathrm{n}}\right]$ defined by the system closure into its domain or state space. The indefinite recursion of component interactions, sustained through systemic re-entries, has the central role in the flux of constitution of the system. (Francisco referred to Wiener who introduced the fundamental revolutionary concept of feedback).

As we are considering real physical processes, the scientific paradigm for such a concept, beyond a general theory of systems, would be biophysics. The whole dynamical process that organisational closure defines can thus be represented, in a very general way, by a system of non-linear differential equations:

$$
\dot{x}=S(x, p, t)
$$

including the set $x$ of co-dependent variables, the set of interaction laws $S$, and a space of internal and external parameters $p$ (we have drawn the generic properties of such a system in Figure 1). If in such a formalism the closure remains implicit, "the stability of a dynamical system can be considered as the representation of the operational closure of an autonomous system" (Varela, 1979).
} 
subjacent processes, for Francisco they are "purely pedagogical." 10

Francisco considered it important to envision the system from the perspective of "its operation, which always unfolds in the present, as in every determined system" (Varela, 1979). He emphasized the "necessity to understand that cognition or behaviors are operational phenomena without final cause: they work in a particular way. Intentionality is an interpretation of the observer. Coherence is a fact and not a "supposed design"" (Varela, 1986b). As we have already noted, for Francisco, the only interactions being carried out in organisms on the level of continuous processes are mechanistic ones.

Thus, the vital "bringing forth" (Varela, 1990) exhibited in living beings, (that we perceive, for instance, as a struggle for life), can be seen as purely a consequence of their mechanical operation: "the closure and the identity of a system are imbricated in such a way that an operationally closed system necessarily subordinates every transformation to the conservation of its identity" (Varela, 1979). This maintaining of identity is a result of its operation, not finality. Thus, from a mechanical point of view, what we observe as intentional behaviors are, Francisco claimed, simply the operational persistence of specific processes (Varela, 1980a). From the point of view of closure, "a system is adaptive simply because its organization is maintained invariant through changes of structure which do not violate constraints."
(Varela, 1984a). In a purely descriptive account, an intentional act, as it appears to the observer, is a mechanical succession of dynamical processes of convergence toward a certain state, a transitory persistence of the coupling between the system and its environment.

This notion of persistence, which is related to stability and has its origins in operational closure, was fundamental to Francisco's characterization of the organism as a bringing forth of an identity. Such identity is maintained in spite of all the perturbations that affect it. In this sense, we can say that it possesses somehow a certain force of inertia (Varela, 1997a). ${ }^{11}$.

In order to account for the "bringing forth" (Varela, 1990) carried out by living systems, we will use the concept of "dynamic core" (Edelman and Tononi, 2000), although it is not a term Francisco used (the issue is developed on the scale of brain dynamics in Michel Le Van Quyen's paper here) ${ }^{12}$.

\section{The eigenbehaviors and the dynamic core}

Although it is fundamentally characterized by its organizational identity, every living system shows specific structural transformations, some of which correspond to what we usually call behaviors. The internal, dynamical side of this observable ethology ${ }^{13}$, from Francisco's purely operational, non-functionalist perspective, is the presence of self-organizing dynamical tendencies shaping the ongoing, specific

\footnotetext{
${ }^{10}$ Francisco always criticized "the naive use of information and purpose," which indicates a "lack of a theory for the structure of the system [...] of a theory of the kind of machines living systems are" (Varela and Maturana, 1973). They do not belong in the definition of the system itself. Against a purely functional characterization of the system leading to teleological views (certainly useful for communication, but lacking the nomic intermediate), he always gave priority to "material interactions," prediction and causality (through a network of nomic relationships). However, Francisco considered the role of observer in the constitution of meaning to be irreducible: "The theory illuminates the subject, and the subject is what makes theorizing possible" (Varela and Goguen, 1977). He sometimes admitted the concept of teleonomy, i.e. causal processes under abstraction, and, in a collaborative work with Andreas Weber he supported some form of teleology in biology. They distinguished between external, seemingly purposeful design, which was Darwin's main concern, and an intrinsic teleology that, on the contrary, is concerned with the "internal purposes immanent to the living." In relation to this latter case, they defended the idea that one can go beyond the simple "as-if character" of natural purposes and grasp "immanent teleology as a truly biological feature." (Weber and Varela, 2002)

${ }^{11}$ The notion of inertia was explicitly present in his work on immune networks: "All these observations are consistent with the notion that the prevalent state of affairs in the lymphoid system has an inertia, which resists attempts to induce sudden and profound deviations in its course of events" (Vaz and Varela, 1978).
}

12 The term was introduced by Edelman in brain -centered meaning (Edelman and Tononi, 2000). Here we will use it in a more general sense. 
"attitudes" of the system. Francisco called them "eigenbehaviors" (own-behaviors) (Varela and Goguen, 1977; Soto-Andrade and Varela, 1984). Eigenbehaviors are specific, preferential, internal transformations that are recurrent in the state space of the system (Fig 2). They possess the following properties: a) an eigenbehavior is a global observable state of the autonomous system under study; b) it is specified by the organizational closure of the system; c) it expresses the coherence of the system's operation; d) it relies on internal cooperative interactions; e) it is not separable from the history of structural coupling of the system with its surroundings. The richness and complexity of a system is therefore based on the intricacy of its landscape of eigenbehaviors.

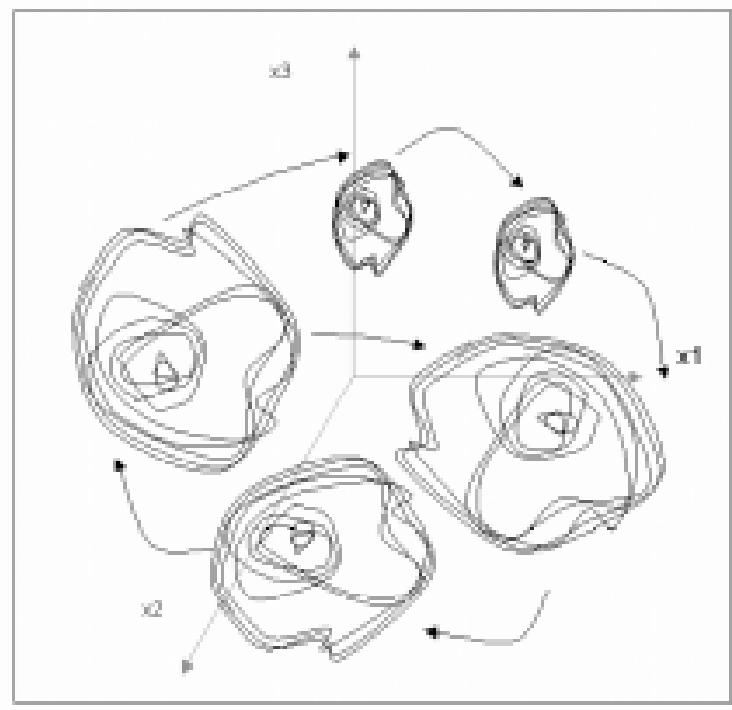

FIGURE 2 - The eigenbehaviors and the dynamic core.

Living systems are dynamical systems. They show ensembles of eigenbehaviors, i.e. a specific ethology. Always transient, such eigenbehaviors can be seen as unstable dynamical tendencies in the trajectory of the system, represented here in an abstract state space. They suggest the existence of self-organizing dynamical laws mechanically producing, through internal cooperative interactions, the richness of the system's behavior and constituting its "dynamic core." (see Le Van Quyen, 2003, in this issue for technical developments)
Michel Le Van Quyen discusses (this issue: Le Van Quyen, 2003) how such generic or systemic properties are fundamental for orienting our search for scientific tools that address the issue of the dynamic core. Francisco studied the notion of eigenbehaviours using concepts issuing from mathematical and physical paradigms such as chaos, complex systems, dynamical systems theory, morphodynamics, selforganizing criticality, synergetics, far from equilibrium thermodynamics, coupled nonlinear oscillators, etc. All of these paradigms provided tools for operationalizing and understanding the emergence of dynamical regularities in living systems, and their tendencies to shift from one to another of their preferential regimes. Concepts like attractors in phase space (or state space), differentiable flow, morphodynamical field, phase transitions, bifurcations, fluctuations etc. constitute powerful tools for characterizing the dynamical properties of living systems.

The central nervous system as a closed network

The brain occupied a central place in Francisco's theory. Given the nervous system's complexity and its properties of connectivity, the brain stands out as an ideal candidate in the living world to actually embody a foundation for the dynamic core and to play a critical role in the self-organization and complexity of the system's eigenbehaviors.

Francisco's more recent views on brain dynamics (Varela et al. 2001; Varela $1995 b)^{14}$ are rooted in conceptions he developed earlier in his work (Varela, $1977 b)$, that were influenced by "new" convergent trends: the re-discovery of the issues around self-organization in physics, and the re-discovery of self-organizing procedures in AI (neo-connectionism). In 1979, he was already interested in

${ }^{13}$ Here the term ethology is used in a very general sense; it can be as complex as is imaginable in order to account for all observable behaviors, up to the human ability to create. It can be plastic, i.e. possess a capability of self transformation through adaptive metadynamics with a highly non linear determination, allowing progressive changes in the organizational closure itself. 
"explaining the emergence of large scale coherences in complex neural-like nets," emphasizing that "statistical reasoning could be used to characterize generic behaviors of the network" (cf. Varela, 1986a).

Following Maturana (1969), and using the same logic used for autonomous systems in general, Francisco proposed "moving towards viewing the brain as a system characterized not by its inputs, but by the operational closure of its dynamics of states," as a complement to the computationalist view on cognitive processing (Varela, 1984b; Varela, 1977b). Francisco and Maturana insisted on the closed and recurrent character of brain organization: "the nervous system is an operationally closed network of neurons in interaction" (Varela, 1979).

Although the central nervous system appears to the neuroanatomist as a very hierarchical and differentiated system with strong functional divisions (such as the sensory-motor division), its internal recursiveness led Maturana to state: "the nervous system, as a mode of organization, seems to begin at any arbitrary point that we may choose to consider" (Maturana, 1969). Inspired by Erich von Holst and Mittelstaedt, Francisco referred to the highly recurrent neuroanatomical structure of brain networks as the "Law of Reciprocity": "if a region A-say, a cortical area, or a specific nucleus-connects to another region $B$, then $B$ connects reciprocally back to $A$, albeit by a different anatomical route."

The kinds of operations taking place in the brain depend strongly upon its interconnectedness, its recurrent graph of connectivity, showing very specific, reciprocal (neuroanatomical) mappings between various distributed internal brain surfaces, with highly differentiated subnetworks. As a consequence of these massive re-entries (reciprocal connections), the brain shows a sustained endogenous activity (cf. Edelman and Tononi, 2000). Examples of this are the oscillatory behaviors elicited by the intertwining of the reticulo-thalamo-cortical networks, the cortico-cortical networks and the corticostriato-thalamo-cortical networks, which can be indirectly observed through the brainwaves in EEGs or MEGs. Neural eigenbehaviors emerge from among these endogenous oscillations through distant, non-linear, recursive interactions in distributed neural networks (Varela et al, 2001; cf. Le Van Quyen in the same issue). ${ }^{15}$

We note here that, as for organizationally closed systems in general, closure in the brain is not incompatible with openness. The central nervous system is, of course, open to interactions with the body and its surroundings in a circular mode, as will be extensively developed in the following sections on embodiment. The vision of the brain as a "closed" network, as emphasized here, is intended to highlight its power of endogenous spontaneity and selforganization. Such closure appears naturally as an important source of organization of the system's dynamic core.

\section{Autonomous systems are mutually embedded subsystems}

Through the concepts of autopoiesis and operational closure we have introduced the general characteristics of the kind of machines humans are: autonomous systems. As the example of the brain as a closed system that is nonetheless open to its environment has shown, one of the features stressed by Francisco is that we are constituted of many embedded sub-systems in interaction (Fig 3).

An organism (and this is particularly true for higher organisms) is composed of highly

\footnotetext{
${ }^{14}$ It can be noted here that Francisco's work on epilepsy with Michel Le Van Quyen and Jacques Martinerie actually became for him a laboratory for studying, at a fundamental research level, the properties of the dynamical patterns in the brain.

15 The need to elucidate the coherence of behavior and cognition, and, in particular, sensory-motor coordination, led Francisco to hypothesize mechanisms of internal coherency, involving self-organizing regulation of temporal relationships in the brain system. This brought him to the hypothesis of "ensembles of transiently correlated neurons," working in the system, that are both "the source and the result from the activity of sensory and effector surfaces" (Varela, 1991). These views have been extensively confirmed (cf. Varela et al, 2001 for a review).
} 
differentiated structures and organizations, including many long distance physiological interactions between the multiple subsystems it contains (for example organs, on a macroscopic scale, and cells on a microscopic one). The autonomous system as a real biophysical entity is spatially and functionally distributed. Moreover, the interactions are costly in time and energy; thus one can consider the many sub-systems in the organism as having a certain autonomy relative to others. Some subsystems have a certain degree of closure due to both their specific internal processes and time constants, and to the long-range connections that restrict possible interactions among sub-systems to a finite delay. According to Francisco, this relative autonomy is particularly obvious in the immune network and the nervous system.

Naturally, the definition of a "sub-system" is always somewhat arbitrary. ${ }^{16}$ For instance, in an autonomous framework, the brain, as a sub-system, can be viewed as a controlled system that is hierarchically dependent on the rest of the system, the individual body. Yet the brain can also be seen as an "autonomous" center of behavioral organization for the body: "the nervous system, the body and the environment are highly structured dynamical systems, coupled to each other on multiple levels"; they are "mutually embedded systems" (Thompson and Varela, 2001).

It can be deduced from such a circular distributed framework with multiple different embedded time constants and biophysical pathways of interactions, that autonomous systems are fundamentally recurrent systems with delays. This multiplication of the recurrent levels of interaction can be a source of selfperturbation in the system, the properties of which we will look at later in this article.

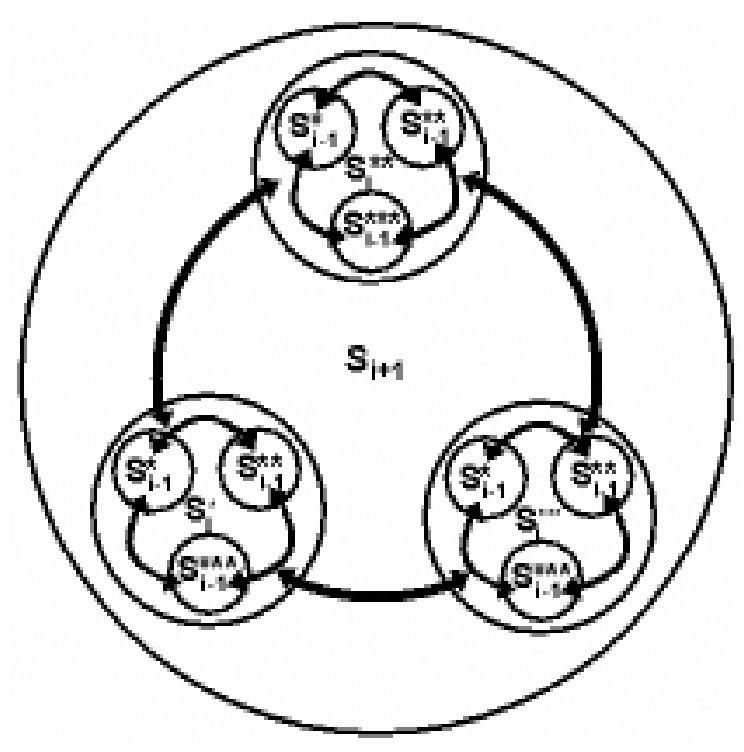

FIGURE 3 - The autonomous system as a mutual embedding of subsystems.

Diagramatic evocation of a "hierarchy" of system levels: systems $S_{i-1}{ }^{*}, S_{i-1}{ }^{* *}, S_{i-1}{ }^{* * *}, \ldots$ of level $(i-1)$ constitute system $S_{i}^{j}$ at level i; similarly, systems $S_{i}^{*}$, $S_{i}^{* *}, S_{i}^{* * *}, \ldots$ of level $i$ constitute system $S_{i+1}$ at level $(i+1)$; and $S_{i+1}$ together with other systems of level $(i+1)$ will constitute a system at level $(i+2)$; and so on, upward and downward. The organism is thought of as an organizational closure of interacting subsystems.

Such an embedded organization, with the high level of constraints of mutual influence between distributed sub-structures (involving a finite time of propagation in physiological, biochemical, or even biomechanical networks) makes the system's dynamics highly non -linear ${ }^{17}$. Since the identity of the system depends on the dynamics of its mutually embedded systems, it is perpetually at risk of breakdown, of divergence; it is, so to speak, "operating at the edge of chaos." Identity is intrinsically precarious and intrinsically fragile. ${ }^{18}$

\footnotetext{
${ }^{16}$ At the level of the whole system it is difficult to define a hierarchy of relations: "At a given level of the hierarchy, a particular system can be seen as an outside to systems below it, and as an inside to system above it: thus, the status (i.e. the mark of distinction) of a given system changes as one passes through its level, in either the upward or the downward direction. The choice of considering the level above or below corresponds to a choice treating the given system as autonomous or controlled (constrained)" (Goguen and Varela, 1979).
}

17 These notions that Francisco developed are certainly very general, but have to be considered in the context of the precise physiological specifications of a given system, with all the integrated sub-systems it includes (the specificity of its organizational closure) that define the functional relations it has in the different contexts it encounters. 


\section{SELFLESS SELF, EMBODIED MIND}

After having sketched out the basics of Francisco's theory of autonomy and operational closure, two actors take on particular importance in his approach: the whole individual as an autonomous system and a fundamental level of organization, and its brain, as an organizing embedded sub-system.

In this section we will try to specify how Francisco conceived the "shaping" of a mind within such a framework of autonomy and circular causality by means of a first step towards the concrete phenomenology of the embodiment. It is indeed essential to keep in mind that we are not only talking about an abstract way of dealing with the fundamental properties of the living, but also about our own organizational and dynamical condition in the concrete domain of our flesh, which is at the root of our experience (Varela et al, 1991).

Francisco's entire conception of mind and ultimately of experience is concerned with the constraints exerted by the specific phenomenology of our concrete coping (Varela, 1999b) upon our internal dynamics as autonomous systems, and reciprocally, the effects of the latter upon the former, in a circular framework. Thus, his approach is grounded in "the disenchantment of the abstract" and the "re-enchantment of the concrete" (Varela, 1995a). He rejected purely computational, logical, views of the mind in favor of a "concrete, embodied, lived" description of the processes. In keeping with his systemic framework, his approach to embodiment proposes an original way to define the problematic "locus" of the mind.

\section{Basics of Embodiment}

According to Francisco, if we want to understand what the mind $i s$, it is not enough to observe the specific brain structures involved in the functioning mind. There is a gap in terms of insight when we try to make the realm of mind fit into a brain structure or even into a brain response. This does not mean that some parts or subprocesses of the system are not more crucial than others for the emergence of subjective experience and consciousness, just as there are organs that are more vital than others. Certainly, the loss of certain parts of one's body or one's brain (after an accident for instance), does not generally lead to the disappearance of the properties that make us "minded" subjects (although often they appear very altered); nonetheless some substructures in the brain, as well as some specific processes, appear crucial and limiting for the constitution of mind or the possibility of consciousness. ${ }^{19}$ These substructures are only critical nodes for the mind's functioning. They cannot be the mind itself. ${ }^{20}$

Such considerations led Francisco to a dramatic conclusion: "the mind is not in the head" (Varela, 1999b; Thompson and Varela, 2001).

The domain of constitution of the mind must therefore be sought in "brain-bodyworld divisions" and certainly not in "brainbound neural events": "we conjecture that consciousness depends crucially on the manner in which brain dynamics are embedded in the somatic and environmental context of the animal's life, and therefore that there may be no such thing as a minimal, internal neural correlate whose intrinsic properties are sufficient to produce conscious experience" (Thompson and Varela, 2001).

The first step, Francisco claimed, is to consider that "the mind cannot be separated from the entire organism. We tend to think that the mind is in the brain, in the head, but the fact is that the environment also includes the rest of the organism; includes the fact that the brain is intimately connected to all

\footnotetext{
${ }^{18}$ Thus, at the level of system/environment interactions, Francisco stressed the notion of "contretemps" between the autonomous system and its surroundings.

19 This has been well demonstrated by neuropsychology (see Damasio, 1994, 1999).

${ }^{20}$ Along the same lines, the philosophical fiction of a brain isolated in a bath with a functioning and conscious mind was an absurd idea according to Francisco. It would just produce incoherent activity (Varela, 1999b).
} 
of the muscles, the skeletal system, the guts, and the immune system, the hormonal balances and so on and so on. It makes the whole thing into an extremely tight unity. In other words, the organism as a meshwork of entirely co-determining elements makes it so that our minds are, literally, inseparable, not only from the external environment, but also from what Claude Bernard already called the milieu intérieur, the fact that we have not only a brain but an entire body" (Varela, 1999b). As a consequence of closure, this irreducible embodiment of our biophysical structure appeared to Francisco as a radical prison : "We can't get out from the domain defined by our own body and our nervous system. Only one world exists for us: the one we are experiencing by these physiological processes that make us what we are. We are taken in a cognitive system, from which we can't neither escape, nor chose where it begins or how it works" (Varela, 1988a).

We frequently talk about sensory-motor or action-perception loops. Francisco is known for his enactive approach, in which the system's "coping" is described as 1) mediated by perpetual sensory-motor loops and 2) mediated by the ongoing endogenous pattern of its brain activity, defining the specific "coupling" of the system with its surroundings (Varela et al, 1991) (Fig 4).
In his last article with Evan Thompson (Thompson and Varela 2001), he proposed the concept of "cycles of operation" referring to the multi-level specific phenomenology of the individual concrete operations taking place during integrated sequences of behavior, in which cognitive acts and mind take place. Through a highly specific phenomenology, the cycles of operations include, notably, organismic regulation, ongoing sensorimotor coupling, cognitive acts and inter-individual interactions (Thompson and Varela, 2001). The drama of the "cycles of operation" occurs, therefore, within a very particular field of constraints, that of the entire organism and its surroundings.

The minimal level of the operational cycles is thus the brain-body system. Francisco described early on the generic circular causality between brain and body as follows. 1) The organism, including the nervous system, is the physical and biochemical environment of the autopoiesis of the neurons and other cells. It is therefore a source of physical and biochemical perturbations which transform the properties of the neurons and lead to couplings 2 and 3.2) Certain physical and biochemical states of the organism transform the state of activity of the neural network by acting on the membrane

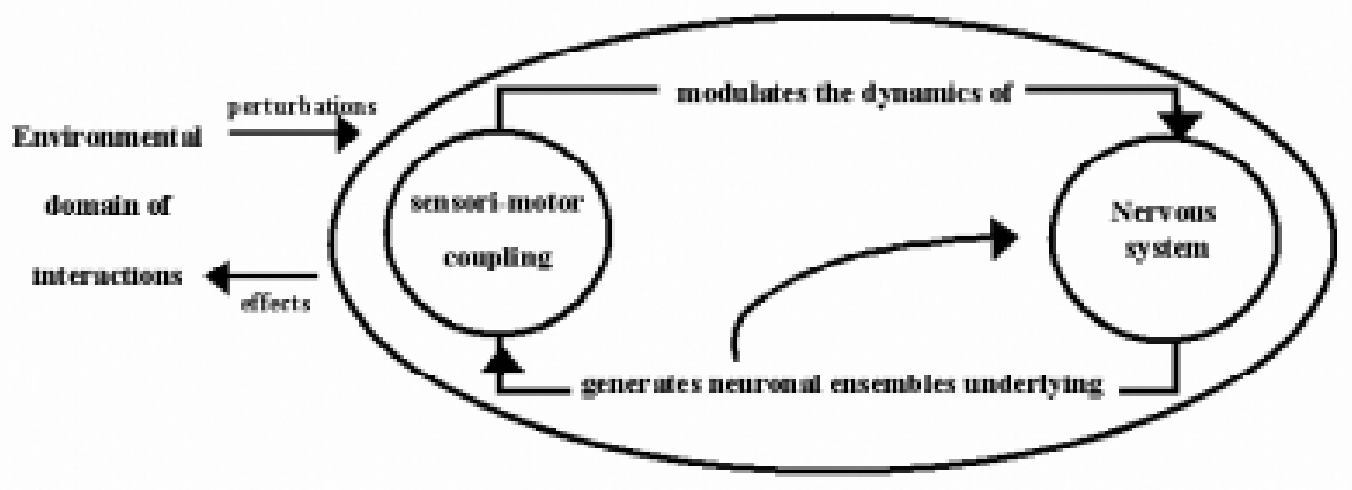

FIGURE 4 - The operational closure of the embodied system.

As a circular process, an individual is engaged in the continuous cycles of operation defined by its eigenbehaviors. Three levels of circular causality are distinguished in the figure: (i) the level of the central nervous system as a closed dynamical system; (ii) the level of the sensory-motor mutual definition of the state of the brain and of the body; (iii) and the level of the ongoing coupling between the autonomous system and its surroundings, including potential inter-individual interactions. 
receptors of certain neurons, leading to the coupling 3.3) Certain states of the nervous system change the state of the organism and lead anew to couplings 1 and 2. (Varela, 1979).

As implied by the enactive approach, this embodied (brain/body) conception of the mind's functioning through cycles of operation, that include at a certain level subjective sequences, does not, of course exclude the grappling with the environment. The embodied mind is not a "solipsist ghost" (Varela, 1991). It works in the "body-inspace," which contributes to its shaping. The ongoing, endogenous regimes of activity in the brain embedded in the rhythms of organism regulation and physiology, must be conceived as taking place within a constant sensory-motor coping between the system and its surroundings: "animality invents a mode of being which is inseparable from movement, going towards, seeking in movement" (Varela and Depraz 2000).

In accordance with the views of the philosopher Merleau-Ponty, the sensory processes of the brain are conceived in direct relation to the organization of the motor eigenbehaviors of the whole system, i.e. its ethology. Motor behaviors define how sensory interfaces will be modulated in a specific situation: "the state of activity of sensors is brought about most typically by the organism's motions" (Varela, 1991). Thus, given this intimate link between brain activity and action, we must consider the "situatedness" of the autonomous systemits particular engagement in specific situations-as fundamental to the "neurologic."

From the standpoint of Francisco's enactive perspective (Varela et al, 1991), the system lends significance to its surroundings, creates a meaningful world through its organizational closure, a world that the environment doesn't possess by itself: "like jazz improvisation, environment provides the "excuse" for the neural "music" from the perspective of the cognitive system involved" (Varela, 1991). But if, in Francisco's view, the environment doesn't contain pre-defined information that is independent of the "domain of coupling" that the autonomous system defines, it literally in-forms the system's coping ${ }^{21}$.

As a complex, distributed, circular biophysical system that is self-affirming, "the body is the place of intersection of the different identities emerging from closure, which makes it so that inside and outside are intricated. We are and we live in such an intertwined place. Our body doesn't have a single external identity alone but constitutes a meshwork divided and intertwined without any other solid foundation than its own procedural [processuelle] determination" (Varela and Cohen, 1989).

\section{So, what is embodied?}

The notion of "cycles of operation" (Thompson and Varela, 2001) conceptually circumscribes the deployment of the embodied mind as a process that takes place in a context of constant coping. It provides the understanding of mind with a kind of "unity of action," that evokes its dynamical status and temporal extension. Here we will look more closely at how Francisco approached the issue of the locus of this embodied mind. The central problem is therefore how to define the correct level of existence of what we intuitively call the mind.

The term itself, em-bodiment, refers to something immanent to the system, shaping its way of being in the world, its way of being coupled. In Francisco's view, cognition was nothing other than this dynamical "coupling" (Varela, 1981; Varela, 1983). From a phenomenological point of view, in our daily apprehension, our mind appears as a very integrated

\footnotetext{
${ }^{21}$ Francisco considered, from a strictly operational point of view, that interactions between brain and environment through sensor-motor interfaces could be seen more as perturbations of an autonomous endogenous dynamics than as the processing of external information: "the fundamental logic of the nervous system is that of coupling movements with a stream of sensory modulations in a circular fashion" (Varela, 1991).
} 
phenomenon, which extends beyond conscious experience; it behaves as a global phenomenon actively asserting its identity, our identity, with a certain autonomy. We could say that, as such, the mind behaves as a self-concerned cognition, or, in the framework of autonomous systems, a mode of persistence, i.e. a dynamic core, associated with a way of interacting, often with itself.

Francisco liked to use intuitions from our daily experience, and considered it as a valid domain of investigation. He illustrated the irreducible "global" nature of the mind as embodied through the way we as humans interact among ourselves. For you, I'm an entity that interacts with you in a noncompact temporal process (if you look at the precise phenomenology of our interactions): my answers to your questions, as you can see when you are waiting for them, take time; my mind's operations take time. My concrete mind also acts as an actual though indirect level of coupling, which you can perceive through our sustained exchange and communication, that involves a global synergy of corporal operations engaging me as an individual. This global level of me as an individual appearing in our mind-related interactions is "a mode of existence of which you cannot say it doesn't exist. ('Francisco doesn't exist')", and without which nothing real would remain of what leads you to see me as minded or imbued with a subjectivity. There is a domain of mutual coupling and mutual determination in which the personwhole is brought forth. This ontological level of the behaving whole in my body cannot be denied. As soon as you try to reduce it to independent sub-systems, you lose it. This resistance to reduction is the direct expression of its systemic nature. Francisco claimed: "I'm an integrated, more or less harmonic unity that I call 'myself' or 'my' mind, and you interact with me at that level: 'Hi, Francisco.' That interaction is happening at the level of individuality, which is the global, the emergent. Yet we know that the global is at the same time cause and consequence of the local actions that are going on in my body all the time" (Varela, 1999b). Thus, from both the biophysical and the concrete experiential points of view, there is no central "I," other than the one sporadically actualized in a linguistic, self-referential mode in communication. The "I" can only be localized as an emergence but it acts as the center of gravity of the subject himself, of his real-life experience"(Varela, 1993).

So, "if the mind is not in the head, where the hell is it?" The answer takes the form of an enigmatic paradox: "[that's] precisely the point here: it is in this non-place of the co-determination of inner and outer, so one cannot say that is outside or inside" (Varela, 1999b). My mind is a "selfless self" (or "virtual self"): "a coherent whole which is nowhere to be found and yet can provide an occasion for coupling" (Varela, 1991). Because of its radical embodiment, the mind is not a substantial mind: "The mind neither exists nor does it not exist [...] it is and it isn't there" (Varela, 1999b). Finally: "it does not physically or functionally reside anywhere" (Varela, 1997c).

If we want to insist on looking at the mind objectively, as a "cycle of operation," that we can describe, we might be satisfied with considering it as a spatially and temporally distributed process that behaves in a way that corresponds to a "mind." The mind as a phenomenology in action, viewed from either a first- or a third-person perspective, can be described as a behavior, literally situated in a specific cycle of operation. Francisco thus conceived of it as a "behavioral cognition" working "at the level of a spatially behavioral bodily entity" (Varela, 1991). The notion of "behavioral cognition" equates having a mind with having a particular behavior. Francisco asserted that each of us, as a "minded" living being, is a dynamical process open to interaction with others and itself. The "locus" of the mind is an "emergence through a distributed process" within the organizational closure. But, as a process of organization, "a non-substantial self can nevertheless act as if present, like a virtual interface" (Varela, 1991).

Here we must be careful not to misinterpret Francisco: as we said earlier, he had no doubt as to the mechanical origin of this global entity. "Virtual entity" 
(Varela, 1997c) or not, dualism and functionalism are excluded. As stated in the first section with respect to the fundamental expression of embodiment, all wholeness in the physical space is the organizational closure of its parts, and, as such, is radically embedded in its interacting constituents and processes and is continuously generated by them. Mind is an aspect of the "pattern in flux" in which our concrete, biophysical being lives (Varela, 1999b). It depends on multiple levels of constitution, and is a way in which the system is coupled within itself and with the environment.

As such, it conserves the general properties of the autonomous systems described above. That is, the mechanical conservation of an identity, brought forth by an internal dynamic core, in a specific embodiment, giving rise to a history of coupling through the particular coping of the system with its environment, defining regularities and making a particular being in the world. As a biophysical process of "bringing forth" identity, it is not surprising that phenomenologically our mind has a self-affirming quality. Physically, this operation of "bringing forth" can be related in part to the non-linear dynamics of the brain, since the brain is the strongest source of self-organization in us and the most plastic one: "the operational closure of the nervous system then brings forth a specific mode of coherence, which is embedded in the organism. This observable coherence is a cognitive self: a unit of perception/motion in space, sensory-motor invariances mediated through the interneuron network [...] the cognitive self is the manner in which the organism through its own selfproduced activity becomes a distinct entity in space, but always coupled to its corresponding environment from which it remains nevertheless distinct" (Varela, 1991). ${ }^{22}$ Thus, from the point of view of the external observer, the experimentalist for example, who must voluntarily distance himself from the natural coupling with his object, this cognitive self evokes the embodied waves of an active dynamic core reverberating through the entire living body. Its determination, or persistence remind us of what we usually think of as will.

As embodied acting selves, we are a global dynamical process, in a dynamical equilibrium, emerging and acting from interactions of constituents and interactions of interactions: "organisms, those fascinating meshworks of selfless selves, no more, nor less than open-ended, multilevel circular existences, always driven by the lack of significance they engender by asserting their presence" (Varela, 1991).

However, Francisco viewed the body as a dynamical "locus where a corporal ego can emerge" (Varela and Cohen, 1989). This issue of the ego giving rise to a sense of self must be situated in Francisco's theory in a very particular field of causality, that shapes embodiment.

\section{The morphodynamical field and its dialectics with the dynamic core}

With the notion of the cycle of operation we have begun to specify the nature of the system's coping and the notion of the selfless self as a dynamical, embodied expression of the dynamic core at work in the individual. But how does the selfless self take on a form so that it "looks like" our experience from the inside? The lived ego of the embodied mind must be thought of as the continuous shaping of the dynamic core. But again, beyond the basics of the specific medium of our embodiment sketched above, it is essential to understand the levels of causality at which the embodied coping, that constitutes our mind, occurs. One of the fundamental sources of shaping, according to Francisco, was the body shape itself: " the most specific property of multicellular organisms is to show a form. This last one gives a body to their operational closure and become the key to understand many dimensions of their operations" (Varela, 1988b).

\footnotetext{
${ }^{22}$ Here we should note how close Francisco's conceptions about the importance of the body and the interactions between the brain and the body in the "making of consciousness" are to Damasio's $(1994,1999,2001)$.
} 
If there is a "reciprocal determination" (Varela and Frenk, 1987) between global structures and parts of systems, as the hypothesis of closure implies, the specific structural and morphological organization of the body must have a "structuring" causal role. According to Francisco, shapes or forms in themselves, of the whole body as well as of its parts, should have a causal role in the dynamics of the system. They are an "ongoing medium" and a "specified/ specifying space:" "The intuition behind our framework is that space is a constitutive element in the dynamics of living organisms just as much as the solidity of their molecular constituents" (Varela and Frenk, 1987).

Now, we are dealing with what we could call a "dense" living body, perpetually acting, moving, transforming from one eigenbehavior to another in its cycles of operation, in such a way that more than external shape, it is the global morphodynamical behavior of its integrated structures which appears central to the way it behaves as a whole autonomous organization. The field of embodiment is a morphodynamical field. ${ }^{23}$ In Francisco's framework this concept complements the more general notion of organizational closure. Applied to the issue of embodiment, it emphasizes the constraints that instantaneous morphological states of the body can exert on the whole system. Of course in the case of a biological organism this is an abstraction which must be conceived of as acting through specific functional or biomechanical pathways in a specific organizational closure.

Francisco called for "a research program in which to understand biological shape," and its "morphodynamical constraints" (Varela, 1988b). Such morphodynamical constraints can be found in the biomechanical degrees of freedom of a specific body, defining a limited set of possible behaviors, as well as in its specific visco-elastic responses to perturbations. The dynamics of internal liquids are also very important. Francisco considered that the extracellular matrix (ECM) - the extracellular medium which forms a "continuum" and links all the body parts to make a whole-was a very important biomechanical medium for morphodynamical causality: "As in the notion of a field and its corresponding particles, there is in living shape a dynamic complementarity: the entire global shape of the body affects the local conditions for the ECM/cell relationship, but at the time the local dynamics conditions how the entire body is actually built" (Varela and Frenk, 1987) ${ }^{24}$. The body organs and tissue mechanics as well as the properties of deformation of the muscular-skeletal and tegument systems should also play a fundamental role in the shaping of the endogenous dynamics of the whole system. All these levels of mechanical causality can affect the whole system and its dynamic core through the interconnections of its organizational closure, i.e. through nervous, hormonal and mechanical pathways. At the most integrated level, posturology can be understood as an initial or boundary condition for the enactive dynamics of the system, to which the internal morphodynamics of the brain's eigenbehaviors, in a shaped sensorymotor coupling, responds.

Within such a framework, the "cycles of operation" referred to above become "morphocycles" (Varela and Frenk, 1987). With each sensory-motor cycle in the behavior of the system, a morphocycle is completed, with its causality potential on the evolution of the system's dynamics.

This potential for effective dynamical deformations through the shaped closure of the system is an important point in the consideration of the constitutive role of the

\footnotetext{
${ }^{23}$ Morphodynamics was developed by the French mathematician René Thom and applied in France to cognitive sciences by Jean Petitot (cf. Petitot, 1992), in order to address the physics of natural forms. The notion of field comes from physics, designating the structure of laws of interaction within a space. Although highly developed by Thom and Petitot in many fields, including biological morphogenesis, and for the later study of self-organization in neural networks, the application of morphodynamics to the issue of mind embodiment is barely under construction and is still seeking precise operationalizations.

${ }^{24}$ It can be noted that such mechanical influence of morphological constraints on the cell dynamics (cell growth, differentiation, secretion, movement, signal transduction, and gene expression) has been demonstrated and related to mechanotransduction through the tensed network of the cytoskeleton in the cell, which can be considered to be a tensegrity system, a contraction of "tension" and "gravity" (cf. Ingber, 1997 for a review).
} 
body in the subjective properties of a system. Shaping its embodiment, it constrains the possible view from within, as a biomechanical horizon instituting a dialogue, (that may, potentially, contain conflicts), within the brain and between the brain and body dynamics ${ }^{25}$.

\section{Reciprocal causality in embodiment}

Francisco was looking for some essential aspect of mind processes in the global operation of the system, viewed not only as an emergent property but also as an organizing (and therefore causal) factor. In this section we will go into more detail on this issue, which is related to the global/ local levels of causality in the embodiment of mind. In keeping with the paradigm of autonomy, the basic idea is to cut through the opposition between vitalism and reductionism by considering the mechanistic braiding together of the local and the global in the determinism of the individual.

Francisco is known for his emergentist point of view on cognition, but he was always distrustful of certain uses of the notion of "emergence." This notion, he said, is often "gifted with some mystical ability" (Varela, 1971). Initially, Francisco associated the notion of emergence with the connectionist paradigm, which he considered as limited (for epistemological reasons that we won't discuss here), emphasizing that emergence simply corresponds to the appearance of global behaviors, patterns resulting from local interactions in networks, through relaxation processes. Emergence was a fundamentally upward phenomenon in Francisco's thinking, working from the local to the collective (Varela, 1990) ${ }^{26}$. Only in his later works (Thompson and Varela, 2001), for purposes of simplification, he did not limit the notion to upward phenomena.

In order to embody the idea of a causal role of global-level processes in physical systems, Francisco proposed early on the notion of "reciprocal causality between the local rules of interactions, (i.e. the component rules, which are akin to chemical interactions), and the global properties of the entity, (its topological demarcation affecting diffusion and creating local conditions for reaction); these relations have the same organizational effect of boundary conditions as does autopoiesis" (Varela, 1991). Reciprocal causality means that there is "two-way traffic" between upward causation (initially "emergence") and downward causation or "downward effect" (Varela, 1990; Varela, 1999b; Thompson and Varela, 2001). ${ }^{27}$

Here, the notion of cause does not have the local value of "efficient causation," but that of "structuring causes," "context sensitive constraints" (Thompson and Varela, 2001) that shape the response properties of the system as in a field. This idea was already well developed in Not one not two (1976). ${ }^{28}$

\footnotetext{
${ }^{25}$ As a result of the organism structure, the morphodynamics of the system should also be subject to the constraints of delay transmission in the system. Shape cycles could be consequently subject to constraints of propagation through the functional pathways of the system. Transformations of the whole system could work somehow as inertial propagative waves flowing into its recursive structure, affecting the dynamic core in a delayed mode. The consequences of such an idea will be developed in the last section of this review in order to gain insight on what we have called at the beginning of this article, the Nagel Effect, the hypothetical subjective effect of having objective processes, i.e. of purely spatial-temporal processes.

${ }^{26}$ In emergence, interconnected simple units can form complex systems and give rise to "a powerful and integrated whole, without the need for a central supervision" (Varela, 1991). Emergent processes are at work in many scientific domains: lasers, chemical oscillation, cells, genetic networks, development, genetics of populations, immune and neural networks, ecology and geophysics.

${ }^{27}$ At the scale of the cell, the downward effects can be found in its topological demarcation, which affects diffusion and creates local conditions for reactions (Varela, 1997a), or in "changes in control parameters and boundary conditions" (Thompson and Varela, 2001), i.e. in "the constraints on the local interaction due to the global coherence" (Varela, 1999b).

${ }^{28}$ In this article he proposed the conception of the global and local relationships, although in an asymmetrical relation, as a "duality" in which the two levels mutually specify each other: the system / the process leading to it. Francisco proposed even the notion of "trinity," in a pure logical sense (he was working on arithmetic), without any spiritualist meaning, to characterize this relation: not a new synthesis, but "just expressions of a relation" of co-dependence, in which a "bottom-up evolution" and a "top-down devolution" take place between the two levels.
} 
We thus have a bootstrapping of two terms: (i) a dynamical term that refers to an assembly of components in network interactions that are capable of emergent properties: metabolic nets, neural assemblies, clonal antibody networks, linguistic recursivity, mind, consciousness ; (ii) a global term which refers to emergent properties, including consciousness (Thompson and Varela, 2001), which (downwardly) condition the network components: cellular membranes, sensorymotor body in space, self/non-self discrimination, personal 'I', and "the two terms are truly in a relation of co-definition" (Varela, 1991). ${ }^{29}$

\section{Holism/reductionism: a false controversy}

To understand the groundwork of Francisco's thinking about embodiment and causality it is necessary to lay out some important aspects of his "epistemology." His epistemological thought is anchored in his particular point of view on systems and, in particular, in the issue of global/local relations. It is particularly important to keep this in mind, in order to guard against spiritualist or vitalist interpretations of his thinking. He is known to be have a nonreductionist position about consciousness or wholeness, but his non-reductionism has a very specific significance in his theory. It concerns global/local and organization/ structure relationships in a framework that is perfectly compatible with mechanistic accounts.
As we have seen, Francisco claimed that circular processes of closure offer the best approach for understanding the living. He distinguished this point of view from the usual input-output approach of Cognitive Science. He always stressed that "clearly these two views (input and closure) are not contradictory, but the important point is to recognize that they lead to radically different consequences, and to radically different experimental approaches as well" (Varela, 1984a).

He considered both reductionism and holism to be erroneous points of view. The correct position is one that considers the mutual dependency of the two domains of explanation which, in fact, are for him definitively complementary. ${ }^{30}$

\section{NEUROPHENOMENOLOGY}

The first two sections have followed Francisco's constructive pathway from the emergence of biological identity to its complex evolution into human embodied cognition. The general properties of the biophysical organization in which we subsist as a circular dynamical process have been discussed with reference to concepts such as autonomy, operational closure and circular causality. Objective considerations about the properties of autonomous systems allowed us to understand the generic bases of the emergence of a self, and helped to set up the domain of explanation by emphasizing that the problem is radically dynamical. The organism's identity,

\footnotetext{
${ }^{29}$ The distinction between the two levels is somewhat artificial, but it is a theoretical distinction for gaining insights into, for instance, the properties of a living being and its mind embodiment. In the real working of the system, all is continuous circular processes.

${ }^{30}$ With respect to the complementarity of the approaches, Francisco emphasized that: "to consider hierarchical non-circular interactions is quite possible, but they cannot account for the re-entering ones, which can, instead, be seen to arise from them by an infinite approximation. Thus the study of forms, open or closed, is a ground, on which there is a superation of the dichotomy holism/reductionism" (Varela and Goguen, 1977). In another article he explained: "It is not that one has to have a holistic view as opposed to reductionist view, or vice versa, but rather that the two views of systems are complementary [...] there is a strong current in contemporary culture advocating "holistic" views as some sort of cure-all [...] Reductionism implies attention to a lower level while holistic implies attention to higher level. These are intertwined in any satisfactory description: and each entails some loss relative to our cognitive preferences, as well as some gain [...] there is no whole system without an interconnection of its parts and there is no whole system without an environment" (Varela, 1977a). The two ways of considering the properties of a system, reductionist and holistic, can be compared respectively to a hierarchical tree or pointed graph description versus a network (or graph) description. Both approaches are mathematically equivalent and quite complementary, as can be demonstrated by the existence of morphisms from one to another (Varela and Goguen, 1977). The difference lies in the recognition of specific levels of organization (cf. also Goguen and Varela, 1979).
} 
construed as a dynamical "bringing forth" in an embodied and situated field, has illuminated the mind problem by positioning it as a complex dialectic between a dynamic core and the morphodynamical field of the body, emphasizing in Francisco's theory the radical intertwining of subjectivity and biophysics. Yet, it is important to highlight that, so far, the point of view of the organism has been studied and characterized from the outside, by an observer who basically relies on his/ her own experience of being alive and conscious in order to infer the internal point of view of the agent.

Francisco thought that the precise modalities of this intertwining between our subjective experience and its biophysical roots should be addressed with a rigorous methodology taking fully into account the concrescence of the experiential and phenomenal domains.

\section{The issue}

Francisco insisted on the importance of considering the constitution of "experience from the point of view of the subject himself, a lived world" (Varela, 1999d). For Francisco, first-person events are "the lived experience associated with cognitive and mental events" (Varela and Shear, 1999b). ${ }^{31}$ This is the starting point of Neurophenomenology and the level at which all our questioning necessarily begins.

In neurophenomenology, one now deals with a pragmatic approach where the observer, the experimentalist, explicitly takes into account a subject's point of view, conceived as situated and embodied in its own individuated space and time (Bitbol,
2002; for an empirical illustration see Lutz et al, 2002).

As we mentioned before, Francisco had a non-reductionist position concerning "subjective experience" in that he rejected the eliminativist position. ${ }^{32} \mathrm{He}$ also rejected any a priori overrating of subjective experience. Mysterianism (Nagel 1974), which claims that the limitations of our cognition make insoluble the hard problem, leads nowhere.

On the contrary, his approach was grounded in the postulate that in many of its aspects, human experience is not so subtle, evanescent and non-communicable that we cannot circumscribe it. In fact, Francisco postulated the existence of a relatively fixed and finite structural architecture of experience: "we are similarly assuming that human experience (mine as well as yours), follows fundamental structural principles which, like space, enforce the nature of what is given to us as contents of experience" (Varela, 1996). ${ }^{33}$

Although non-reductionist in the sense mentioned above, Francisco's proposal goes beyond the simple search for the "neurobiological (brain or bodily) correlates of consciousness" because simply studying correlates would "leave in the shadow the precise circulation between them" (Varela, 1997b). It would amount to just "putting on one side a list of items or processes, and on the other seeming equivalencies as phenomenological data and separating the two sides by a "mystery" line, a no-man's land left unexamined" (Varela, 1997b). Francisco promoted naturalizing phenomenology as well as "phenomenologizing" neuroscience (Varela, 1999a). i.e. not to reduce consciousness but "re-enchant" the concrete of biology itself.

\footnotetext{
31 "the processes being studied (vision, pain, memory, imagination, etc.) appears as relevant and manifest for a 'self' or 'subject' that can provide an account; they have a 'subjective' side." (Varela and Shear, 1999a).

${ }^{32}$ We must look for a "non-reductive explanation" in the sense that, in the end, it mustn't lead to an "elimination" of experience, what we want to account for : "What should a natural science become to be fully adequate to phenomenological descriptions that could be naturalized but not epistemically reduced" (Varela, 1997b).

${ }^{33}$ We can read also in the same article: "Do I expect the list of structural invariants relevant to human experience to grow ad infinitum ? Certainly not. I surmise that the horizon of fundamental topics can be expected to converge towards a corpus of wellintegrated knowledge."
} 
The explanans, the domain of explanation, the "locus of circulation" for neurophenomenology" (Varela, 1997b), is naturally embodiment : "data rooted in firsthand experience are intrinsically open to a non-reductive naturalization. This is the central thesis that animates the neurophenomenological research project, which is only possible if the central issues of embodiment are put at the center of concern both for cognitive science (such as the enactive approach) and in phenomenology (such as in the later work of Husserl and its continuation in MerleauPonty). In fact, it is in the lived body broadly conceived that one finds "the close relationship" between experience and its grounding (as both Leib and Körper). It is in that region of events that we are given access to both the constitutive natural elements familiar to cognitive science and the required phenomenological data." (Varela, 1997b). ${ }^{34}$

\section{A methodological remedy for the hard problem}

Neurophenomenology is grounded on a pragmatic will to progressively and systematically "reduce the distance between subjective and objective [...] a way of narrowing the gap between the mental and the physical" (Varela, 1997b). ${ }^{35}$

In this perspective experimental paradigms and rigorous first person methodologies must be developed in order to "examine experience." This involves "breaking with the taboo of using phenomenal data as valid" (Varela, 1999b) and according phenomenal data (Roy et al, 1999) a place as important as that of objective, neurodynamical, neurophysiological, or biophysical data. ${ }^{36}$

However, a simple undisciplined introspective approach is not the solution; the 'just-take-a-look' or 'seeing inside' attitude must be overcome. Neurophenomenology implies "gathering a research community armed with new pragmatic tools for the development of a science of consciousness." This involves a "call for transforming the style and values of the research community itself," in other words, that researchers themselves, as they are specialists in neurosciences for instance, become specialists in the phenomenology of conscious experience: "My proposal implies that every good student of cognitive science who is also interested in issues at the level of mental experience, must inescapably attain a level of mastery in phenomenological examination in order to work seriously with first-person accounts" (Varela and Shear, 1999b).

The idea is that developing the "skill of phenomenological description" is like developing a "know-how," like "learning to play an instrument or to speak a new language"; it is a concrete "training" (Varela and Shear, 1999b). Francisco wanted to initiate within the Cognitive Science "a sustained tradition of phenomenological examination" cultivating "a systematic capacity for reflexiveness" in "our habitual mind stream" 37 .

A fundamental aspect of this "training" is that "[it] must be done in the context of a

\footnotetext{
${ }^{34}$ The problem of "naturalizing phenomenology" (Petitot et al 1999) can be set out as one of the intertwining between the Leib and the Körper, German terms, both meaning "body," used by Husserl to distinguish respectively the subjective and the objective sides of our embodied condition (Varela, 1996).

${ }^{35}$ On its methodological side, neuro-phenomenology is an " experiential neuroscience " (Varela, 1999b), it " is the name I use here to designate a quest to marry modern cognitive science and a disciplined approach to human experience" (Varela, 1996).
36 The expression "phenomenal data" is introduced as a "common first-person/third-person ground" for experience, (third- person referring here to the objective characterization of experience). In his classical acceptance, a phenomenon expresses that "something is for something else; it is a being for by opposition to a being in itself independently of its apprehension by another entity" (see Varela and Shear, 1999).

${ }^{37}$ Such mechanisms could be fully investigated through a closer examination of experience itself. As he noted: " there are, numerous instances where we perceive phenomena pre-reflexively without being consciously aware of them, but where a 'gesture' a method of examination will clarify or even bring these pre-reflexive phenomena to the fore. (...) what is being objected here is the naive assumption that the demarcation line between the strictly subpersonal and the conscious is fixed. ." 
disciplined approach to the intersubjective validation of conscious experience" (Varela and Shear, 1999b). Subjective experience is not completely a "private experience," it can be "shared." Between the first-person account and the third-person point of view, we can work with an intermediate mediation, a "second-person position," "an empathic resonator" (Varela and Shear, 1999a).

Two main long-standing traditions were deeply influential for Francisco. He found in "contemplative traditions" the model par excellence of a rigorous pragmatics for the investigation of consciousness: "We explicitly draw from Asian traditions, Buddhism in particular, as living manifestation of an active, disciplined phenomenology. It [is] not the intention [...] to dwell on Asian traditions per se but to use them as a distant mirror of what we [need] to cultivate in our science and the western tradition" (Varela, 1996).

On the other hand, he drew extensively on the work of philosophers like Husserl, Heidegger, the Kyoto school and MerleauPonty. These philosophers produced accurate operational descriptions of subjective experience and, in particular, Husserl (cf. Husserl, 1970) proposed a general technique for investigating consciousness, making it "recognizable" (Varela, 1996): the Phenomenological reduction $(\mathrm{PhR})$. In fact, Francisco considered that the husserlian corpus could constitute a research program in itself, a "husserlian neurophenomenology" (Varela, 1997b) ${ }^{38}$.

In the specific framework of neurophenomenology, Francisco sketched the process of reduction as:

1) Attitude. a "self-induced suspension of reference to the contents" ${ }^{39}$, followed by a "redirection of thought" towards the "process of constitution" of the contents themselves. The attitude is then to "[cut] short our quick and fast elaborations and beliefs, in particular [...] putting in abeyance what we consider we think we 'should' find, or some 'expected' description. Thus $\mathrm{PhR}$ is not a 'seeing inside', but a tolerance concerning the suspension of conclusions that allows a new aspect or insight into the phenomenon to unfold" (Varela, 1996). Furthermore, we must try to make the self-observing reflexive acts as automatic and discrete as possible, as in certain contemplative states, its horizon being a "'pure' (contentless) consciousness" (Varela and Shear, 1999b). ${ }^{40}$ The gesture of reduction can either be self-induced or guided by a mediator through open questions (Depraz et al 2003). In the latter case such questions invite the subject to redirect his/her attention towards the implicit know-how he/she implemented to carry out the task, or towards the texture of his/her experience during its deployment.

2) Intuition. Phenomenological reduction involves a gain in intimacy towards the phenomenal domain of investigation. The validation of the pertinence of the experience is therefore grounded on its intuitive "evidence" (as in mathematics): "This gain in intimacy with the phenomenon is crucial, for it is the basis of the criteria of truth in phenomenological analysis, the nature of its evidence" (Varela, 1996). For Francisco: "Intuition is not some fluffy stuff."

3) Invariants. A process of description must follow in order to define phenomenological invariants. Such an extraction of invariants supposes a work on controlled "variations" of the subjective experience, what Husserl called "eidetic variations" in order to specify "the appropriate dimensions of mental states" (Varela, 1996). These descriptive structural

\footnotetext{
${ }^{38}$ Phenomenology "allows the foregrounding of a unique universal property of mental phenomena, namely the manner in which they are, in fact, conscious" (Varela, 1997b).

39 This letting go of the "natural attitude" was referred to by Husserl as an epoche, a suspension of judgements.

${ }^{40}$ It is evident that such a reflexive act involves in itself supplementary internal processes, but the effect of this addition to the habitual working of consciousness could be experimentally controlled, and self-observation is a quite natural attitude, which constitutes in itself a very interesting field of research.
} 
invariants must be open to intersubjective validation. Evidence is shared evidence; intersubjectivity is central.

4) Training. In order for the method to serve as a concrete pragmatics: "If one does not cultivate the skill to stabilize and deepen one's capacity for attentive bracketing and intuition, as well as the skill for illuminating descriptions, no systematic study can mature." ${ }^{41}$. Thus training is a fundamental aspect that recursively permeates the proposed methodology at each step. Specific phenomenological states must be investigated through multiple "redone" experiences by the researcher himself. The search for stability naturally opens up the possibility of working with trained expert subjects capable of reproducing internal conscious states in experimental situations.

\section{Phenomenological invariants: the formal level}

Simple verbal reports are very interesting but, in the end, they are limited. The nature of phenomenological descriptions resulting from reduction is essential: "Putting into proper relevance the structural invariants of experience opens the door for the right domain of formality" (Varela, 1997b). The formal level (Varela, 1999b) appears thus as a fundamental aspect of neurophenomenology.

The adequate spaces of representation for the description of phenomenological experience must be defined in relation to its very nature. Subjective experience appears as a complex multidimensional flux with emergent salient moments of perceptions, thoughts, imagination, mnesic representations, vigilance variations, attentional shifts, emotional changes, etc. Cognitive operations are embodied in dynamical processes with a temporal texture that is essential in their phenomenology. Consequently, phenomenological descriptions call for "a dynamical picture" (Varela, 1997b): invariants are dynamical.

From this perspective, Francisco made a "strong" parallel between phenomenology and mathematics (Varela, 1997b). Through his personal phenomenological exploration, he described subjective experience as a real dynamical system. For him the dynamical system paradigm, was the right "bridge" (Varela, 1999a) between the two realms. It is clear that in order to provide operational phenomenological invariants, Francisco was looking for a mathematization of phenomenology. ${ }^{42}$ "The critical role of formal tools is, in short, based on the Janusfaced nature of mathematical ideals: they provide eidetic invariants which can, in turn, be immediately linked to a naturalistic embodiment or implementation." (Varela, 1997b). ${ }^{43}$

\section{Mutual constraints}

Francisco described the pragmatic approach of reducing "the distance between subjective

\footnotetext{
${ }^{41}$ He said: "This last aspect of the PhR [Phenomenological reduction] is perhaps the greatest obstacle for the constitution of a research program since it implies a disciplined commitment from a community of researchers" (Varela, 1996).

42 The exigency of dynamical representations for the phenomenal data had not been really completed in the experimental works already directed by Francisco (presented below). The first way to provide with a true dynamical picture of the relationships between subjective experience and brain-body processes would be to compare temporal series of brain-body dynamics with temporal series of subjective experience. This has caused us to work today as a team on the development of specific interfaces that allow subjects to provide forms of accounts other than verbal ones, for instance, curves describing the temporal course of their emotional feelings, and to address the problem of the objective temporal reference of the subjective experience (Varela, 1997b)

43 A five-step process thus emerges: 1) phenomenological data; 2) descriptive invariants; 3) mathematical models 4) mathematical descriptions 5) naturalistic implementations (Varela, 1997b). The level of formal description becomes a new common level or language of description between first person and third person data, intended to "make the image of a global workspace into an explicit mechanism" (Varela, 1997c). Besides, in Francisco's view, it works as a third dimension in the pragmatic space of investigation: "we seek to produce epistemological and ontological shifts whereby the two domains of natural objects and phenomenological descriptions can provide a three-dimensional view of mind and experience altogether" (Varela, 1997b).
} 
and objective" as a search for progressive mutual determination, constraints or circulation: "We need to advance a cognitive science where there is a true circulation between lived experience and the biological mechanisms in a seamless and mutually illuminating manner" (Varela, 1996).

Biophysical or neurodynamical investigations should help to illuminate the domain of subjective experience by constraining it: "it is an axiom that we can only experience what corresponds to our organization" (Varela, 1976). They should also help to validate phenomenological accounts by demonstrating their implementation.

Reciprocally, the domain of subjective experience is the tool for defining what we want to account for, (the structure of consciousness) and for guiding our definition of compatible physical processes. For instance, the dynamical phenomenology of consciousness made Francisco look for a particular type of dynamical neurobiological process. Phenomenology thus becomes a central criterion for the validation of hypotheses about its physical determination: "the novelty of my proposal is that disciplined first-person accounts should be an integral element of the validation of a neurobiological proposal, and not merely coincidental or heuristic information" (Varela, 1996).

Francisco was looking for a profound level of intertwining, at which the relations between both domains would become clear: "this mutual reciprocity without residue is the very nature of the region unique to the körperleib" (Varela, 1997b) (cf. footnote 33).

This belief in the heuristic value of such an experimental intertwining was formulated as a working hypothesis:

Working Hypothesis of
Neurophenomenology: Phenomenological accounts of the structure of experience and their counterparts in cognitive science relate to each other through reciprocal constraints (Varela, 1996).

The dialectic approach of mutual constraints must be seen as a pragmatics intended to provide "generative passages": "the isomorphic idea [between subjective and objective levels] is taken one step forward to provide the passage where the mutual constraints not only share logical and epistemic accountability, but they are further required to be operationally generative, that is, where there is a mutual circulation and illumination between these domains proper to the entire phenomenal domain" (Varela, 1997b).

In Neurophenomenology the subject clearly has a double status: he/she is and acts as a subject in a particular task, but the subject also needs to know about his/her own experience in order to report structural features about his/her experience. Francisco was aware that such a situation raised a fundamental issue: Neurophenomenology requires some degree of self-awareness, even implicit, to provide phenomenological descriptions and structural insights. But this very process of becoming self-aware required by the task could be said paradoxically to introduce unwanted complexity in the data and at the same time to be the very process that science tries to account for. To integrate this aspect of human experience necessarily involved in the implementation of mutual constraints, Francisco proposed exploring experimentally this gesture of "becoming aware" itself (cf. Depraz et al, 2000). The complete presentation of this issue is beyond the scope of this review (for a recent development see Lutz, 2002).

Francisco was 52 years old when he formulated the neurophenomenological proposal. Despite the fact that he would have only two short years to live, he was able to make significant advances in the essential theoretical and experimental foundations of this great project.

\section{Neurophenomenology of nowness}

The first objective Francisco proposed for neurophenomenology was the account of the dynamics of time-consciousness and "constitution" (Varela, 1999a): "constitution" is the term used by Husserl in his Phenomenology to designate the process of construction and emergence of a moment of consciousness. Following Husserl, Francisco emphasized the 
distinction between the "content of a mental act" and the "process through which such content appears."

Francisco described moments of consciousness as dense moments of synthesis in the flow of consciousness, in which specific contents appear in an uncompressible duration. ${ }^{44}$ Francisco (Varela, 1999a) took examples from bistable figures to empirically illustrate this "uncompressible" duration of a conscious cognitive act (Necker cube, binocular rivalry, etc.). In these experiments spontaneous transitions between two dominant perceptions appear phenomenologically as "slow" dynamical processes.

Francisco distinguished three scales of lived time (Varela, 1999a): the 1 scale, of about one second, which corresponds to the time of a conscious moment and to which "nowness" belongs; the 1/10 scale corresponding to minimal separable perceptual events; and the 10 scale corresponding to narrative time.

It is important to note that accounting for the existence of conscious experience itself is not the objective at this stage of investigation. The relation between brain processes and conscious experience is postulated and partial accounts of specific aspects of the actual experience are sought. The brain level is only considered to contribute to the properties of conscious experience (we must remember: "the mind is not in the head"). As in the perspective of Edelman and Tononi (cf. Edelman, 2001), the properties of consciousness integration, uniqueness and dynamical fluctuation were stressed as phenomenological invariants whose determinism could be partially accounted for through a neuroscientific investigation on brain processes. ${ }^{45}$

At the phenomenological level the constitution of conscious moments implies a high temporal integration of multiple contents emerging in a transitory way (multimodal integration, for example). This phenomenal integration, accessible from the first-person point of view, suggested that participating brain processes should be integrative and coherent, although transient, on the large scale. For Francisco, such transient organizing synergy of mass action between distant brain regions would bring unity to the conscious moment, but at the same time endow it with a fundamental lack of stability, that would therefore lead to transitions.

As Francisco noticed, the dynamics of such perceptual emergent moments resembled the phenomenon of convergence in dynamical systems followed by relaxed phase transitions. This behavior is typical of multistable dynamical systems, in which eigenbehaviors are constrained by a landscape of multiple non-stable attractors (for a technical description of the notion see Le Van Quyen (2003, this issue). The brain necessarily belongs to such dynamical systems because of its biophysical organization (its organizational closure). Francisco thus looked for integrative mechanisms exhibited by this class of systems. In this perspective, the paradigm of transiently phase-locked coupled nonlinear oscillators, with distributed nonlinear interactions in space and time, provided a good level for modeling. ${ }^{46}$

\footnotetext{
${ }_{44}$ These more or less salient moments of consciousness are described by Husserl as having a specific phenomenal structure. They include a retentional extension, in which the "just-past" seems to plunge slowly away from the field of consciousness, and a protentional openness toward the next moment. Our account here is a dramatic simplification of Husserl 's theory.

${ }^{45}$ A framework of phenomenological simple invariants was proposed by Francisco: 1)Mental events occur in a unitary space ("unified cognitive mental space"); 2) Mental states are transitory ("mental states are finite, and have an incompressible and inextensible duration"); 3) Mental states are always body-bound ("embedded in a particular field of sensation") ; 4) Mental states can be triggered by endogenous events (moreover mental states can be causal, as in the voluntary reversal of bi-stable figures) (Varela, 1995b).

${ }^{46}$ Francisco had been inspired by the classical theory of Hebb (1949) about cell assemblies: "A cell assembly (CA) is a distributed subset of neurons with strong reciprocal connections," such that a local activation of a subset of the assembly gives rise to a sustained ignition of the whole assembly. Francisco distinguished three causal and temporal levels of emergence of CAs: 1) Onto-genetic (the structural neuroanatomical connections); 2) Developmental-learning (related to the metadynamics of synaptic weights under Hebb-like rules); 3) Perception-Action (where fast ignition of CAs gives rise to sustained coherence after a short relaxation time involving cycles of spike transmission between distant regions). He latter favored the notion of neural ensemble or neural hypergraph.
} 
Given the importance of integration in brain activity and in behavior, he proposed that transient phase-locking between brain ensembles could be a fundamental mechanism of large scale integration in the brain (Fig 5). He understood such mechanisms to be a "neural glue" that would enhance a specific distributed neuronal ensemble participating in the emergence of a moment of consciousness. The idea is that "it is the precise coincidence of the firing of the cells that brings about unity in mental-cognitive experience" (Varela, $1995 b){ }^{47}$

Francisco proposed three working hypotheses: 1) For every cognitive act, there

\section{lived moments}

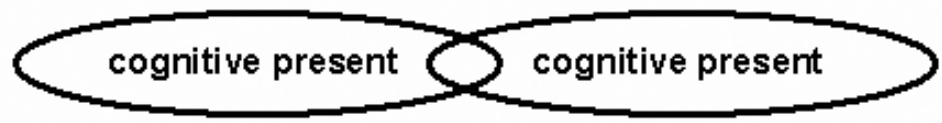

\section{subjective time}

\section{average phase coherence}

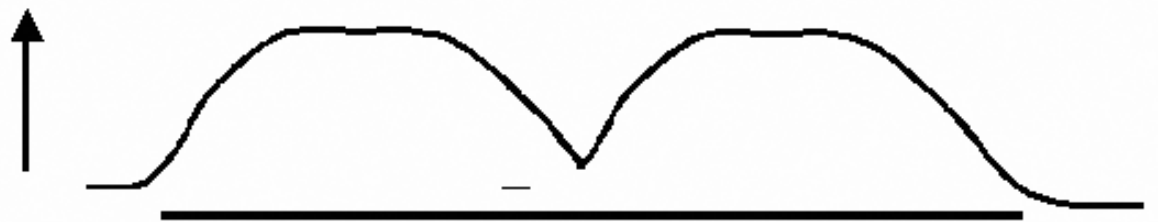

dynamics of synchronous neural ensembles

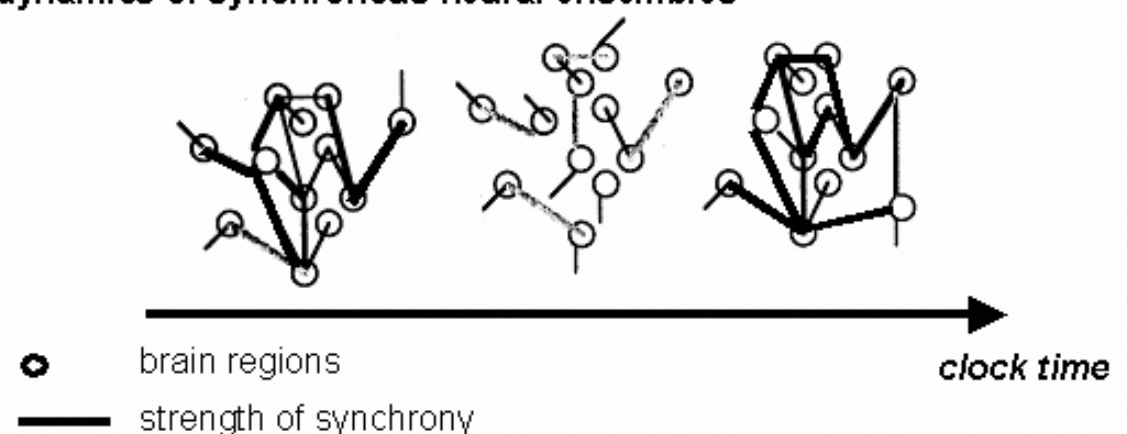

FIGURE 5 - The moments of consciousness.

A diagram depicting the three main hypotheses. A cognitive activity takes place within a relatively incompressible duration, a "cognitive present." The basis for this emergent behavior is the recruitment of widely distributed neuronal ensembles through increased coherence in the gamma band $(30-80 \mathrm{~Hz})$. Thus, the corresponding neural correlates of a cognitive act can be depicted as a synchronous neural hypergraph of brain regions undergoing bifurcations of phase transitions from one cognitive present content to another.

\footnotetext{
${ }^{47}$ The problem of the perceptual binding brought to the fore the importance of dynamical synchronization in the brain to bind independent functional processes in specialized sensory pathways (Singer and Gray, 1995). Damasio also had proposed the mechanism of large-scale synchronization as an integrative process for memory (Damasio 1989). Early on, Francisco and others emphasized the importance of synchronization in the brain perceptuo-motor unity (Varela et al, 1981; Gevins et al. 1983). Abeles proposed that synchronization could play the role of coherent signal enhancement favoring transmission in neural networks (Abeles et al, 1994). Synchronizations are a natural consequence in interconnected systems with multiple long-range re-entries or reciprocal connections. The convergent process which leads to such emergence of phase-locked coherent ensembles is grounded in the fast ongoing oscillations at work in the brain, in which an important role is given to the gamma band $(30-80 \mathrm{~Hz})$, and in the inhibitory-excitatory dynamics of brain networks, not only at the thalamo-cortical level but also at the cortico-cortical one (cf. Varela et al, 2001 and Varela, 1995b for a review).
} 
is a singular, specific cell assembly (CA) that underlies its emergence and operation; 2) A specific CA is selected through the fast, transient phase- locking of activated neurons belonging to sub-threshold competing CAs; 3) The integrationrelaxation processes at the 1 -scale are strict correlates of present-time consciousness. ${ }^{48}$

\section{Experimental evidence}

To study the relations between subjective experience and brain synchronization, mathematical tools for quantifying transient phase-locking between EEG/ MEG signals were developed (Lachaux et al, 1999). The principle was to use complex wavelet convolution of brain signals to extract single-trial instantaneous phase information, independent of amplitude, and to quantify the stability of phase differences in short integration periods.

EEG recordings were obtained from subjects presented with Mooney faces for $200 \mathrm{~ms}$ (Rodriguez et al, 1999), that is, a binary picture representing human faces, easily recognized as faces when presented in upright orientation but usually seen as meaningless black and white shapes when presented upside-down (Fig 6). Subjects had to answer by pressing a button indicating whether or not they had perceived a face during the presentation of the picture. The data was then classified into two groups, the group Perception, and the group Non Perception. In the "Perception" condition, a transient episode of large-scale phase locking between electrodes on the scalp appeared $250 \mathrm{~ms}$ after the presentation of the stimulus. This large-scale synchrony occurred mainly in the gamma band (30-80 $\mathrm{Hz}$ ), and was followed by a strong episode of phase scattering, i.e. desynchronization in relation to the baseline. Only after this scattering, during the motor response, did a new synchronous ensemble emerge. On the other hand, in the Non Perception condition no significant synchronous ensemble appeared after the presentation of the picture. These experiments confirmed the relation between conscious perceptive moments and large-scale neural synchrony in the gamma band.

In a second experiment (Lutz et al, 2002), the neurophenomenological approach was radically developed. Subjects were trained during several experimental sessions to actively categorize their ongoing subjective experience during the 7 seconds rest period that preceded presentation of a three dimensional shape. Trial by trial, they described their experience through verbal accounts, which were recorded on tape. Then, in a dialogue between the experimenter and subjects, phenomenological clusters were defined, with the aim of classifying the invariant aspects of the subjective experience during the experimental sessions. Recording of EEG scalp signals was done in the same experimental framework, and subjects were asked to categorize their experience trial after trial based on the previously defined set of phenomenological clusters. Brain data were regrouped according to phenomenological clusters and a dynamical analysis was performed on each cluster.

The outcome of this experiment is complex and very rich. In a first implementation of this approach, Francisco and Antoine Lutz studied, for instance, how the precise description by trained subjects of their cognitive contexts (attentive state, thought-processes, strategy to carry out the task) could be used to study the intrinsic variability in the brain responses found during the repetitive presentation of the same visual stimulation. By combining first-person data and the analysis of neural processes, the opacity in the brain responses was reduced and original dynamical categories were detected. This case study offers a nice example of how the careful examination of experience using specific first-person methodology could become a heuristic strategy to provide mutual insights

\footnotetext{
48 Considering the requirement of a minimal number of cycles of large-scale interactions for the emergence of a large synchronous assembly correlated to the moments of consciousness, he naturally assumed that the frequency band of phaselocking should be in high frequency domains like the gamma band.
} 


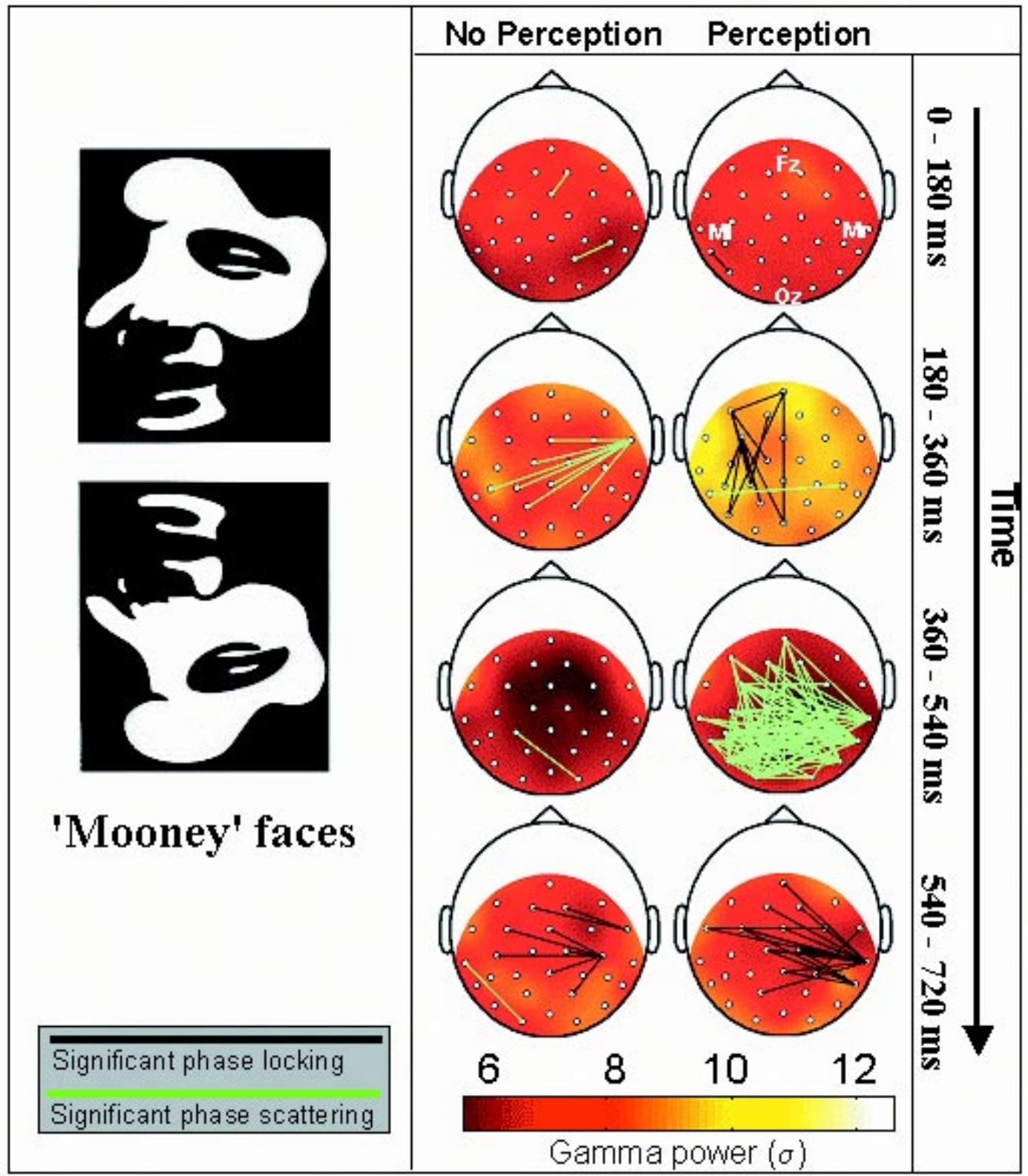

FIGURE 6 - The shadow of perception.

Average scalp distribution of gamma activity and phase synchrony. EEG was recorded from electrodes on the scalp surface. Subjects were shown upright and upside-down Mooney figures (high contrast faces), which are easily perceived as faces when presented upright, but usually perceived as meaningless black-andwhite forms when upside-down. The subjects' task was a rapid two-choice button response of whether or not they perceived a face at first glance. Color-coding indicates gamma power (averaged in a $34-40 \mathrm{~Hz}$ frequency range) from a given electrode and during a $180 \mathrm{~ms}$ time window, from stimulation onset ( $0 \mathrm{~ms})$ to motor response $(720 \mathrm{~ms})$. In the condition where the figures were recognized, transient episodes of largescale synchrony appeared after the presentation of the stimuli, followed by a period of phase scattering and a second period of synchrony during the motor response. Such patterns of synchrony were not present when the pictures were not recognized. Synchrony between electrode pairs is indicated by black and green lines, corresponding to a significant increase or decrease in synchrony, respectively. These are shown only if the synchrony value is beyond the distribution of shuffled data sets $(\mathrm{P}<0.01$; see methods, Ref. 18). (from Rodriguez et al, 1999). 
concerning the relations between first- and third person accounts. To illustrate the discussion, we will present here one such result in which two phenomenological clusters are contrasted for a given subject (Fig 7). In the first cluster (A) the subject typically reported being prepared for the presentation of the stimulus, aware, with a feeling of continuity when the stimulation occurred, and an impression of fusion between himself and the percept. In the second cluster (B), the subject reported being unprepared, distracted, and having experienced a strong discontinuity in the flux of his internal mental states by the presentation of the stimulus. He described a clear impression of differentiation between himself and the percept.

The main result is the correlation between the features of the subject's subjective experience and the dynamical neural signatures (DNS) of the clusters (Lutz et $a l, 2002)$. In the prepared cluster (A) a frontal synchronous ensemble emerges early and is maintained throughout the trial, correlating with the impression of continuity of the subject. Furthermore, the average reaction time (RT) for this cluster is short. In the unprepared cluster (B), no stable synchronous ensemble can be distinguished during the pre-stimulus period. When the stimulation occurs, a complex pattern of weak synchronization and of strong phase scattering (desynchronization) between frontal and posterior electrodes is revealed. Slowly, a subsequent frontal synchronous ensemble appears while the phase-scattering remains present for some time. In this cluster, the $\mathrm{RT}$ is longer. The complex pattern of

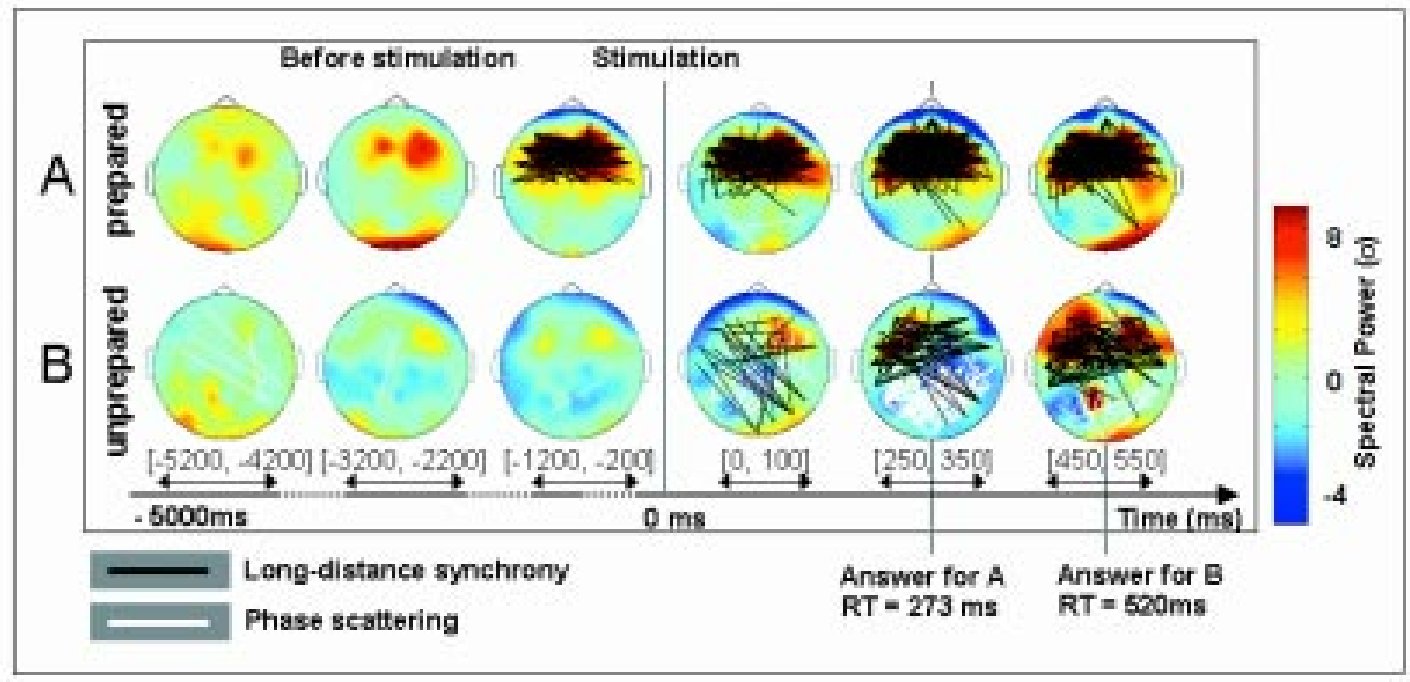

FIGURE 7 - The shadow of perception and feeling within a subjective sequence

EEG was recorded from electrodes at the scalp surface. Subjects were shown first a background image with random-dot points. They were asked to fuse two small squares at the bottom of the screen and to remain in this position for several seconds. At the end of this preparation period, a stereogram (3D illusion) was presented. Subjects were instructed to press a button as soon as the shape had completely emerged and to give a brief verbal report of their experience (see section 2.3). Dynamical neural signatures (DNS) of the precise phenomenology of the subjective experience of the subject are presented: (A) brain dynamics associated with a feeling of mental continuity and readiness (154 trials), (B) brain dynamics associated with a feeling of discontinuity and unreadiness with surprise when the stimulation occurred (38 trials). The observed brain patterns (resulting from the selection of the data on the sole criterion of the ongoing subjective experience of the subjects) show dynamical features well correlated with the phenomenology of the subject's conscious experience: the continuity of the mental correlates with the continuity of the synchronous patterns. Color-coding indicates scalp distribution of gamma power around $35 \mathrm{~Hz}$ normalized compared to a distant baseline ([-8200ms $7200 \mathrm{~ms}], 0 \mathrm{~ms}$ corresponds to the presentation of the stereogram). Black and white lines correspond to significant increase and decrease in synchrony, respectively, compared to the baseline. (Modified from Lutz et al, 2002) 
synchronization and phase scattering could correspond to a strong reorganization of the brain dynamics in an unprepared situation, delaying the constitution of a unified cognitive moment and of an adapted response. This discontinuity in the brain dynamics is correlated with a subjective impression of discontinuity.

As required by the neurophenomenological approach, this study intertwined the two dimensions of phenomenological experience and brain dynamics in a mutual illumination.

However, if the idea of neural phaselocked hypergraphs can provide insight on very specific phenomenal properties of consciousness, such as its coherent integrative role, its spontaneity and the transitions among successive moments, in itself it provides no insight about the constitution of sentience and inner subjective experience, the issue of why we feel like embodied systems.

Toward a biophysics of being: the breakdowns

The question thus arises: "Given that there is a myriad of contending sub-processes in every cognitive act, how are we to understand the moment of negotiation and emergence when one of them takes the lead and constitutes a defined behavior? In more evocative terms: How are we to understand the very moment of being-there when something concrete and specific shows up?" (Varela, 1995a)

Francisco radically reconsiders the situatedness of our cycle of operations, taking their "micro" behavioral phenomenology itself as a fundamental procedural element that shapes our ongoing subjectivity. Our situatedness as human autonomous systems is first to be found in our daily lives: "ordinary life is necessarily one of situated agents." He took seriously the fact that our ongoing activity is made up of "contingencies, improvisation, and [is] more flexible than planning" (Varela, 1991). He emphasized that as mechanisms, we live in the present, in the automatism of most of our actions and procedural acts. The continuity of identity and behavior is a matter of non-conscious dynamical processes guaranteed by the "machine." As enactive systems we integrate automatic behaviors, including chains of reflexes as well as what Francisco called "know-how," procedural actions. We live recurrently in their "transparency": most of the time we don't think about what we are doing, and often we have no real subjective experience of our actions. As Francisco said: "we always operate in some kind of immediacy of a given situation: our lived world is so ready-at-hand that we don't have any deliberateness about what it is and how we inhabit it. When we sit at the table to eat with a relative our body postures and pauses in the conversation are all present without deliberation. Our having-lunch-self is transparent " (Varela, 1995a). This dispositional repertory of behaviors is such that "we have a readiness-to-action which is proper to every specific lived situation," "microidentities," "microworlds," "within which we move during a normal day." This corresponds in human life to what we find in animals as ethology, i.e. eigenbehaviors, of which most are acquired. He referred (Varela, 1999a) to the Heideggerian paradigm of the field of relations and tools in which we are living transparently: turning lights on and off, walking on the street, etc. For Heidegger, cognition and awakening appear when some situation of dysfunction occurs: my key doesn't work in this lock, I don't find my wallet in my pocket.

$\mathrm{He}$ saw the fundamental figure of our daily existence as being the dialectic between transparency of action and breakdowns. Francisco stressed that "cognition is action about what is missing, filling the fault from the perspective of a cognitive self" (Varela, 1995a). Thus, the fundamental micro-figure of experiential constitution, which is always situated in a specific context, is the "shift in transparency" related to breakdown. If we look carefully at our subjective experience, "our 'ordinary experience' is made of breakdowns" in this transparency.

From the first -person point of view, such a situation occurs thus: "Breakdown: you stop, your mind setting is unclear, your emotional tonality shifts. Before you know 
it a new world emerges: you see clearly that you left your wallet in the store where you just bought cigarettes. Your mood shifts now to one of concern for losing documents and money, your readiness-to-action is now to quickly go back to the store [...] all attention is directed to avoiding further delays."

According to Francisco, this caricaturesituation can be applied generally to all our gestures and actions: "new modes of behaving and the transitions or punctuation between them correspond to mini (or macro) breakdowns we experience constantly [...] at each such breakdown the manner in which the cognitive agent will next be constituted is neither externally decided nor simply planned ahead. It is a matter of commonsensical emergence, of autonomous configurations of an appropriate stance [...] such commonsense, then needs to be examined at a microscale: at the moments where it actualizes during breakdown, the birthplace of the concrete [...] during the breakdown there is a "rich dynamics involving the concurrent sub-identities and agents." In this perspective, phenomenology of behavior tends to fit the phenomenology of our subjective experience: "embodied (sensory-motor) structures are the substance of experience." (Varela, 1999a)

The dynamics of neural assemblies presented above could be interpreted from within such a framework. Although dynamically related to the previous moment, they emerge as a breakdown in relation to the previous state of the system. In this perspective, the presence of moments of great phase-scattering between two well separated cognitive acts is very interesting since they are associated with a feeling of discontinuity (Lutz et al, 2002). As noted in Lutz et al (2002) the differentiation in subjective experience is related to microsequences of appearances of discontinuity.

In this light, the fundamental units of constitution of a concrete moment of experience appear to be the activity of coping with impediments, i.e. the coping with very specific micro-situations in our situated cycles of operation, that is, in the present state of our operation as systems.
Such "shaped" breakdowns in cognitive coupling must be envisaged as perturbations of our dynamic core.

To understand how such impeding effects can be lived internally, as sentience, Francisco brought to the fore the field of emotions and affect. Unfortunately, he did not have time to develop fully this last field of his theory. However, by following its internal logic and bringing together the ideas he developed, we can intuit a possible explanation of the final biophysical origin of sentience.

The Nagel Effect: resistance to selfperturbation and sentience

The part of the Francisco's work we introduce here is most likely the least well known, but perhaps the most essential for understanding the biophysical basis of being. Centered on the issue of affects, it permits a synthesis of Francisco's views on embodiment extensively developed in the first part of this article. It might constitute the core of an understanding of what we have called the Nagel Effect, of the subjective experience of having certain physical processes, and so provide us with the conceptual framework for bridging the so-called 'explanatory gap'.

In the last period of his work Francisco (Varela, 1999a; Varela and Depraz, 2000; Thompson and Varela, 2001) was particularly preoccupied with the question of affects and the production of sentience. For him, affect and emotions, "a privileged way for accessing the primordial body" (Varela and Cohen, 1989), played an essential role in mind: "affect or emotion is at the very foundation of what we do every day as coping with the world; reason or reasoning is almost like the icing on the cake. Reason is what occurs at the very last stage of the moment-to-moment emergence of mind. Mind is fundamentally something that arises out of the affective tonality, which is embedded in the body [...] [Mind] starts out from this soup [...] all cognitive phenomena are also emotional-affective" (Varela, 1999b) ${ }^{49}$ Going even further, he considered affect as "generative for 
consciousness itself" (Varela and Depraz, 2000), as a cause of transition from one moment of consciousness to another as well as a cause for the emergence of subjectivity itself.

Since the early days of the development of the concept of autopoiesis, Francisco always rejected the metaphorical use of his concepts, wanting them to be used in precisely defined operational domains. He has been thus reluctant to see the concept of autopoiesis applied to autopoiesis to cultural anthropology or social sciences. Yet in existing metaphors, he often found the opportunity to reveal operant mechanisms by considering their literal meaning. It is in this sense that he mobilizes the concept of affect, which can be considered as a frontier between the realms of objectivity and subjectivity.

He claimed that "affect is a pre-reflective dynamic in the self-constitution of the self, a self affect in a literal sense. Affect is primordial in the sense that I am affected or moved before any 'I' that knows." (Varela, 1999b).

Francisco based his insights about the constitution of sentience on his phenomenological analysis of affects. Starting with the transition between two moments of consciousness (Varela, 1999a), which is always associated, according to his phenomenological experience, with the feeling of a gradually emerging change, he grounded the dimension "of affect-emotion in the self-movement of the flow, of the temporal stream of consciousness." $\mathrm{He}$ emphasized the bootstrap role of emotions through their intrinsic fluctuating character and saw them as control parameters in the initiation of bifurcations between two moments of consciousness: "affect is at the very core of the temporality, and is even, perhaps, its antecedent" (Varela and Depraz, 2000). ${ }^{50}$

In his view, "the emergence of the lived present is rooted in and arises from a $\mathrm{germ}$ or source of motion-disposition, a primordialfluctuation. This germ manifests itself in a constellation: an original tendency, a shift of attention, the emergence of salience, the earliest e-motion including a motion that embodies it. Thus this primordial fluctuation cannot be separated from its complex or multifarious constitution. But it is nevertheless marked by its uniqueness in the unfolding of the living present" (Varela and Depraz, 2000). Inspired by Husserl and James, Francisco and Depraz considered these subjective fluctuations as forces involving whole body transformations: "the affective force manifests as a rapid, dynamical transformation from tendency to salience, involving one's entire leib [lived body] as a complex [...] the gamut of autonomic action such as respiratory, heart rate, endocrine secretion, etc., as well as the ancestral motor pattern involved in posture and movement [...] a feeling grounded in the body's responsive repertoire" (Varela and Depraz, 2000). The feeling of emotion appears as "the global Gestalt composed of a variety of feeling dimensions." The

\footnotetext{
49 He stressed the importance "of the background sensations of the embodiment preceding and grounding all happening cognitive events" (Varela and Depraz, 2000). Francisco distinguished three scale of affect: 1) emotions: "the awareness of a tonal shift that is constitutive to the living present;" 2) affect: "dispositional trend proper to a longer time (hours or days) a coherent sequence of embodied actions;" 3) mood, "the scale of narrative description over a long duration (many days or weeks)."

${ }^{50}$ This importance of emotions in the making of consciousness represented at the same time a difficulty in a methodological perspective for neurophenomenology: "that's why experience in a phenomenological footnote is so hard to articulate, since a large chunk of its base is pre-reflective, affective, non-conceptual, pre-noetic. It's hard to put it into words, precisely because it precedes words."

${ }^{51}$ Such a dynamical storm is not incompatible with the fact that emotions are highly regulated processes. The self-perturbations of emotions are induced in the context of integrated neurophysiological responses. As Francisco stressed, living systems show naturally intrinsic instabilities, which are not incompatible with the preservation of their organizational autonomy. On the contrary these instabilities "are the norm" in biological systems (Varela, 1999a) and play an essential functional role as they allow the system to easily shift from one to another of its eigenbehaviors, i.e. to move the current state of the system and the dynamics to a new configuration, in a catastrophic phase transition (an emotion as a stereotyped neurophysiological response is an eigenbehavior). Instabilities are the foundation of the spontaneity of living beings.
} 
phenomenology of affects ("self-affect" and "primordial fluctuation") provides us with deep insight into how circular causality, through fluctuations and self perturbations in the recurrence of our body space (and its morphodynamical constraints), could give rise to a minimal subjective experience. Because of the very circularity of our organizational closure perturbations can be "self-inflicted" (Varela, 1983). We could say that we are self-perturbing systems. ${ }^{51}$ Our phenomenology of affects could thus be literally understood as a self-perturbing system.

Yet in order to accept this view, one needs to know exactly what is affected. Tradition names this essential part of our experience 'the Subject,' but in Francisco's view the Subject does not represent anything unified. Francisco was very influenced by the Madhyamaka way to look at the self which explicitly says that it is as wrong to say that the subject is real as to say that it is not.

Francisco and Natalie Depraz proposed that the inner lived ego emerges through "the micro-temporality of affect of an originary ego-self, situated in a basic disposition" (Varela and Depraz, 2000). To make this last statement concrete, "Affect" must be here interpreted in relation to the general role attributed by Francisco to breakdowns in moments of consciousness, whose micro-temporality is stressed. The "originary ego-self, situated in a basic disposition", must be thought of in relation to the automatic procedural know-how that operates most of our behavior, i.e. our innate or acquired biological dispositions to react, from the elementary to the most subtle shaping our personality; something, in any case, coming from the machine.

To be completely understood, this idea of an "originary ego-self" that undergoes affect must be considered in Francisco's framework of embodied autonomous systems. According to this framework, the self 'resides' in the selfless mechanical patterns of eigenbehaviors of the dynamic core, emerging from a biophysical and mechanical field of individual autoaffirmation endeavoring to keep a dynamical identity, i.e. a form of systemic invariance. The concrete cycles of operation of the system embody the irrepressible persistence of a biophysical process of selforganization that makes the individual. If we interpret Francisco's views literally, this mechanical bringing forth of the "selfless self" through the flow of its dynamic core occurs as a global process that constitutes a sphere of internal tension and resistance to perturbations (this internal tension can already be seen in the basic vigilance of animals). As an integrative mechanism this very core of resistance works as a more or less automatic system of compensation with an inner, highly specific, morphodynamical set of responses. The compensatory tension resists the circular deformation (usually biologists use the term "adaptation"). It confronts the ongoing round of internal fluctuations and instabilities which act as flux and reflux of self-perturbative forces affecting the dynamic core by propagating through the system closure. Such is the case with emotions, consisting of catastrophic changes in a large portion of the physiology of the organism. Here Francisco's enactive approach can take on its full meaning with regard to the Nagel Effect, i.e. the operation of subjectivity-making.

If we consider them in the framework of the morphodynamics of human body and ethology, we claim that this type of pattern allows us to intuit that there is something that it is like to be such a system, resisting self-perturbations, and so to fill the explanatory gap. We submit that sentience itself, as the prototype of our ability to feel and a concrete moment of consciousness, $i s$ the embodied grappling between the shaped, distributed process that we are and our own morphodynamical deformations.

Although a general mechanism, this particular feature of the repetitive dynamics of the system must be considered as getting its specific phenomenology from the context of its situated daily coping in "microworlds," as introduced above, and in the particular morphodynamical field of its embodiment, with all the biophysical properties of its flesh and behavioral engagement. 


\section{CONCLUSION}

In this article we have reviewed the work of Francisco Varela on the "hard problem" of subjectivity and consciousness. We have followed a constructive approach, starting with Francisco's initial developments on autonomous systems, progressing through his various theoretical specifications of circularity and embodiment that are exhibited by living systems and ending with the neurophenomenological proposal.

We began to explore how the physical autopoietic system provides a minimal description of a living system. The logic of such an embodied autonomy is that of "being the operational closure of its parts" and maintaining an invariant organization, distinguishing itself. But the bringing forth of such an identity as the process of being alive implies a dynamical tendency that unfolds in time. Thus the situated organism finds itself in a circular dialectic between its ongoing dynamics of bringing forth and the necessity to cope, to compensate for perturbations that impact on it either from the environment or from within. This complex interaction, this conflict, between global behavior and local structures in the coping situated agent generate internal forces that impede or even accelerate processes, and their particular phenomenologies, with the quality of subjective experience. As humans we have the possibility not only of accessing but also of communicating such multifarious experiences of being. The need to examine rigorously such phenomenology calls then for a pragmatic approach, where the will to reduce the distance between the subjective and the objective, between lived experience and biophysical processes, is a fundamental theoretical and experimental goal. Neurophenomenology responds by placing experience and biophysical processes at the same level, and by seeking to establish an enlightening circulation in the form of mutual constraints between them.

Francisco's thought is vast and insightful. A great deal of work needs to be done to further interpret his ideas. Many concepts and propositions he made have yet to be studied in depth and made operational in concrete experimental situations. His way of stating problems in an open but explicit manner (Varela, 1996) remains an inspiration for those of us continuing this work.

Among the aspects that need to be explored, in our opinion, there are four themes of fundamental interest for the science of consciousness: the issue of developing the dynamical picture of phenomenological invariants and their prior formalization, (particularly for consciousness spontaneity, sentience and the constitution of the dynamic core); the question of intersubjectivity; that of expert subjects; and the problem of self-awareness.

In our laboratory we are currently developing paradigms and computer interfaces to attain reliable single-trial representations of the temporal course of the lived subjective experience of experimental subjects, in perceptive and emotional tasks. The goal is to find a methodology that provides us with a temporal basis, making it possible to precisely link subjective time and objective time, in order to examine the inter-relations between the two. Complementarily, in the perspective of neurophenomenology, the team is also developing tools for dynamical systems analysis (see Le Van Quyen in this issue) in order to study the relationships between the dynamics of subjectivity and the dynamics of the brain and body. We also work concretely on the issue of intersubjective validations of phenomenological descriptions. Finally, it is interesting to take advantage of the rigorous direct examination of conscious experience that is cultivated by Buddhist contemplative practices. Francisco had initiated such collaboration with highly trained practitioners before he passed away. His project was to study the generation of precise and stable mental states that is well documented in Buddhist psychology. This line of research is now being actively developed by the team.

As a friendly remembrance of Francisco, we would like to conclude this paper with a figure that he used to sketch the story of cognitive sciences and to speculate on their further development (Fig 8). 


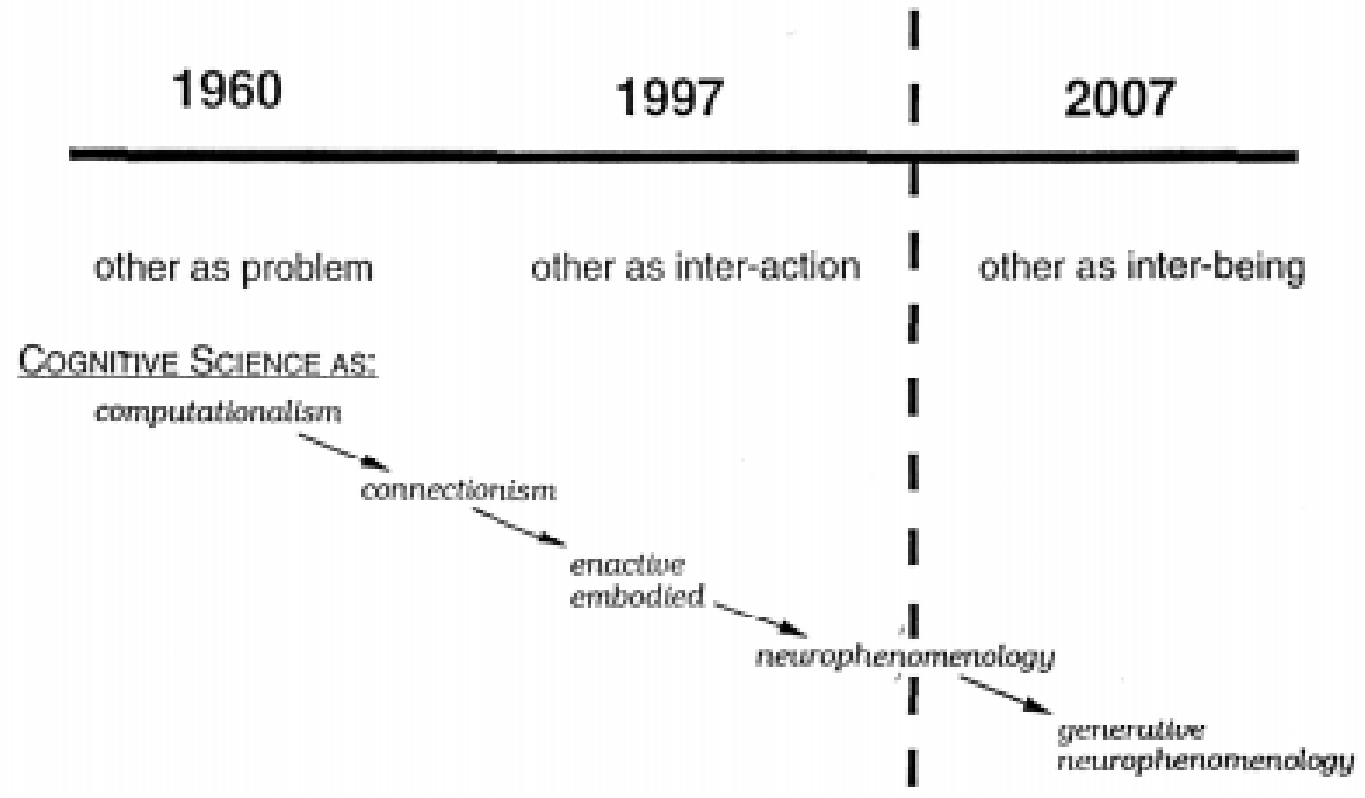

FIGURE 8- The building site: toward a science of interbeing.

Francisco's sketch of the story of cognitive sciences and their further development in relation to neurophenomenology (from Varela, 1999b).

\section{IN MEMORIAM}

This article is dedicated to Francisco Varela in memory of his innovative work, generous teaching and inspiring life.

For his obituary see http:// psyche.csse.monash.edu.au/v7/psyche-712-thompson.html.

\section{ACKNOWLEDGMENTS}

Very special acknowledgments are due to Amy Cohen-Varela who worked hard with us on this text, encouraging the authors and providing essential comments, propositions and deep insights, and illuminating the issues with her remarkable erudition and brilliant understanding of Francisco's thinking. Thanks to Adam Phillips and Jamie Hanson for their careful reading of this paper. Thanks to Christopher Kovach for his precious reading of the paper and suggestions.

\section{REFERENCES}

ABELES M, PRUT Y, BERGMAN H, VAADIA E (1994) Synchronization in neuronal transmission and its importance for information processing. Prog Brain Res 102:395-404 Review

BEAUREGARD M, LEVESQUE J, BOURGOUIN P (2001) Neural correlates of conscious self-regulation of emotion. J Neurosci 21(18) RC165

BITBOL M (2002) Science as if situation mattered. Pheno Cogn Sci 1(2):181-224

BLOCK N (1996) How can we find the neural correlate of consciousness? Trends Neurosci 19(11):456-9

BOURGINE P, VARELA FJ (1992) Towards a practice of autonomy. In: BOURGINE P, VARELA FJ (eds) Toward a Practice of Autonomous Systems. Cambridge, MA: MIT Press/Bradford Books

CHALMERS D (1996) The Conscious Mind: In search for a fundamental theory. New York: Oxford University Press

CRICK F, KOCH C (1998) Consciousness and neuroscience. Cereb Cortex 8(2):97-107Rev

DAMASIO AR (1989) Time-locked multiregional retroactivation: a systems-level proposal for the neural substrates of recall and recognition. Cognition 33(12):25-62 Rev

DAMASIO AR (1994) Descartes' Error: Emotion Reason and the Human Brain. New York: Putnam

DAMASIO AR (1995) Consciousness. Knowing how, knowing where. Nature 375(6527): 106-7

DAMASIO AR (1999) The feeling of what happens: body and emotion in the making of consciousness. New York:Harcourt 
DAMASIO AR (2000) A neurobiology for consciousness. In: METZINGER $\mathrm{T}$ (ed) Neural Correlates of Consciousness. Cambridge, MA: MIT Press

DAMASIO AR (2001) Fundamental feelings. Nature 2001 413(6858):781

DAMASIO AR, GRABOWSKI TJ, BECHARA A, DAMASIO H, PONTO L, PARVIZI, J HICHWA RD (2000) Subcortical and cortical brain activity during the feeling of self-generated emotions. Nature Neurosci 3 (10): 1049-1056

DEHAENE S, NACCACHE L (2001) Towards a cognitive neuroscience of consciousness: basic evidence and a workspace framework. Cognition. 79(1-2):1-37

DEPRAZ N, VARELA FJ, VERMERSCH P (2000) The gesture of awareness: an account of its structural dynamics. In: VELMANS M (ed.), Investigating Phenomenal Consciousness. Benjamin Publishers: Amsterdam

DEPRAZ N, VARELA FJ, VERMESCH P (2003), On becoming aware: a pragmatics of experiencing (Advances in consciousness research, 43). Amsterdam: John Benjamins Publishing Company

DUPUY JP, VARELA FJ (1991) Creative circularities: Understanding origins. In: VARELA FJ, DUPUY JP (Eds.) Understanding Origin, Stanford University Intl Symposium, Boston Studies Phil Sci. Boston: Kluwer. pp: $1-27$

EDELMAN GM (1989) The remembered present: a biological theory of consciousness. New York: Basic Books

EDELMAN GM (2001) Consciousness: the remembered present. Ann N Y Acad Sci 929:111-22 Review

EDELMAN GM, TONONI G (2000) Reentry and the dynamic core: neural correlates of conscious experience. In: METZINGER T (ed) Neural Correlates of Consciousness. Cambridge, MA: MIT Press

ENGEL AK, SINGER W (2001) Temporal binding and the neural correlates of sensory awareness. Trends Cogn Sci $20015(1): 16-25$

FRISTON K (2002) BEYOND PHRENOLOGY: What can neuroimaging tell us about distributed circuitry? Annu Rev Neurosci 25:221-50

GEVINS AS, SCHAFFER RE, DOYLE JC, CUTILLO BA, TANNEHILL RS, BRESSLER SL (1983) Shadows of thought: shifting lateralization of human brain electrical patterns during brief visuomotor task. Sci 220(4592):97-9

GOGUEN J, VARELA FJ (1979) Systems and distinctions: Duality and complementarity. Int J Gen Systems 5:3143

GRAY JA (1995) The contents of consciousness: a neuropsychological conjecture. Behav and Brain Sci 18:659-76

HEBB DO (1949) The organization of behavior; a neuropsychological theory. New York: WileyInterscience

HUSSERL H (1970) The Idea of Phenomenology. The Hague: M. Nijhoff

INGBER DE (1997) Tensegrity: the architectural basis of cellular mechanotransduction. Annu Rev Physiol 59:575-99

LACHAUX JP, RODRIGUEZ E, MARTINERIE J, VARELA FJ (1999) Measuring phase synchrony in brain signals. Hum Brain Mapp 8(4):194-208
LANE R, REIMAN E, AXELROD B, YUN L, HOLMES A, SCHWARTZ G (1998), Neural correlates of levels of emotional awareness. Evidence of an interaction between emotion and attention in the anterior cingulate cortex. J Cogn Neurosci 10(4):525-35

LEVINE J (1983) Materialism and qualia: the explanatory gap. Pacific Phil Quart 64:354-61

LE VAN QUYEN (2003) Disentangling the dynamic core: a research program for a neurodynamics at the largescale. Biol Res 35, this issue

LOGOTHETIS N (1998a) Object vision and visual awareness. Curr Opin Neurobiol 8(4):536-44. Review

LOGOTHETIS N (1998b) Single units and conscious vision. Phil Trans R Soc Lond B Biol Sci 353(1377):1801-18 Rev

LUTZ A (2002), Toward a neurophenomenology as an account of generative passages: A first empirical case study. Pheno Cogn Sci 1(2):133-167

LUTZ A, LACHAUX JP, MARTINERIE J, VARELA FJ (2002) Guiding the study of brain dynamics by using first-person data: synchrony patterns correlate with ongoing conscious states during a simple visual task. PNAS 99(3): 1586-1591

MATURANA HR (1969) Neurophysiology of cognition. In: GARVIN P (ed) Cognition a multiple view. New York: Spartan Books

MATURANA H, VARELA FJ (1973) De Máquinas y Seres Vivos: Una teoría sobre la organización biológica. Santiago: Editorial Universitaria

MATURANA H, VARELA FJ (1980) Autopoiesis and Cognition: The realization of the living. Boston: D Reidel

NAGEL T (1974) What is it like to be a bat? The Phil Rev LXXXIII, 4: 435-50

PARVIZI J, DAMASIO A (2001) Consciousness and the brainstem. Cognition 79:135-59

PETITOT J (1992) Physique du Sens. Paris: Editions du CNRS

PETITOT J, VARELA FJ, PACHOUD B, ROY JM (1999) Naturalizing phenomenology. Issues in contemporary phenomenology and cognitive science. In: PETITOT J, VARELA FJ, PACHOUD B, ROY JM (eds) Stanford, CA: Stanford University Press

RODRIGUEZ E, GEORGE N, LACHAUX JP, MARTINERIE J, RENAULT B, VARELA FJ (1999) Perception's shadow: long-distance synchronization in the human brain. Nature 397:340-343

ROY JM, PETITOT J, PACHOUD B, VARELA (1999) Beyond the gap. An introduction to naturalizing phenomenology. In: PETITOT J, VARELA FJ, PACHOUD B, ROY JM (eds), Naturalizing Phenomenology. Stanford, CA: Stanford University Press. pp:1-83

SINGER W, GRAY CM (1995), Visual feature integration and the temporal correlation hypothesis. Annu Rev Neurosci 18:555-86 Rev

SOTO-ANDRADE J, VARELA FJ (1984) Self-reference and fixed points. Acta Applic Matem 2:1-19

SRINIVASAN R, RUSSELL D, EDELMAN GM, TONONI G (1999) Increased synchronization of neuromagnetic responses during conscious Perception. J Neurosci 19(13):5435-48

THOMPSON E, VARELA FJ (1999) Autopoiesis and Lifelines: the importance of origins. Behav Brain Sci 22:909-910

THOMPSON E, VARELA FJ (2001) Radical embodiment. Trends Cognit Sci 5(10): 418-425 
TONONI G, EDELMAN GM (1998a) Consciousness and complexity. Science 282(5395):1846-5

TONONI G, EDELMAN GM (1998b), Consciousness and the integration of information in the brain. Adv Neurol 77:245-79 Rev

TOOTELL RB, HADJIKHANI NK, VANDUFFEL W, LIU AK, MENDOLA JD, SERENO MI, DALE AM (1998) Functional analysis of primary visual cortex (V1) in humans. Proc Natl Acad Sci U S A 95(3):811-7 Rev

VARELA FJ (1971) Self-consciousness: adaptation or epiphenomenon? Studium Generale 24:426-439

VARELA FJ (1976) Not one, not two. CoEvolution Quart 12:62-67

VARELA FJ (1977a) On being autonomous: The lessons of natural history for systems theory. In: KLIR G (ed) Applied Systems Research. New York: Plenum Press. pp:77-85

VARELA FJ (1977b) The nervous system as a closed network. Brain Theory Newsletter 2:66-67

VARELA FJ (1979) Principles of Biological Autonomy. New York: Elsevier/North-Holland

VARELA FJ (1980) Describing the logic of the living. In: ZELENY M (ed.) Autopoeisis: A theory of the living organization. New York: North-Holland. pp:36-48

VARELA FJ (1981) Autonomy and autopoiesis. In: ROTH G, SCHWEGLER H (eds.) Self-Organizing Systems: An interdisciplinary approach. Frankfurt and New York: Campus Verlag. pp:14-24

VARELA FJ (1983) L'auto-organisation: De l'apparence au mécanisme. In: DUMOUCHEL P, DUPUY JP (eds) L'Auto-Organisation: De la physique au politique. Paris: Editions du Seuil. pp:147-165

VARELA FJ (1984a) Two principles for self-organization. In: ULRICH H, PROBST G (eds) Self-organization and Management of Social Systems. Berlin: Springer Verlag. pp:25-33

VARELA FJ (1984b), Living ways of sense-making: A middle path for neuroscience. In: LIVINGSTONE $P$ (ed) Order and Disorder: Proceedings of the Stanford International Symposium. Stanford, CA: Anma Libri. pp:208-224

VARELA FJ (1986a) Experimental epistemology: Past, present, and future. Rev Internat Systemique 1:209225

VARELA FJ (1986b) Laying down a path in walking: a biologist's look at a new biology. Cybernetic 2: 6-15

VARELA FJ (1987) Les racines biologiques de la individualité. In: Sur L'Individu, Colloque de Royaumont. Paris: Editions du Seuil. pp: 88-95

VARELA FJ (1988a) The creative circle: sketches on the natural history of circularity. In: WATZLAWICK P (ed) L'invention de la réalité. Paris: Editions du Seuil. pp:329-347

VARELA FJ (1988b) Autonomie et Connaissance: Essai sur le Vivant. Paris:Eds du Seuil

VARELA FJ (1990) On the conceptual skeleton of cognitive science. In: BEOBACHTER, FINK W. Munich: Verlag. pp:13-25

VARELA FJ (1991) Organism: A meshwork of selfless selves. In: TAUBER (ed) Organism and the Origin of Self. Dordrecht Kluwer. pp:79-107

VARELA FJ (1993) Le cerveau et la pensée. In: CANGUILHEM G (ed) Philosophe et historien des sciences. Paris: Aubier: pp:279-286
VARELA FJ (1995a) The re-enchantment of the concrete. In: STEELS L, BROOKS (eds) The Artificial Life route to Artificial Intelligence: Building Embodied, Situated Agents. New Haven, CT: Lawrence Erlbaum Assoc. pp:11-20

VARELA FJ (1995b) Resonant cell assemblies: a new approach to cognitive functions and neuronal synchrony. Biol Research 28:81-95

VARELA FJ (1996) Neurophenomenology: A Methodological remedy to the hard problem. J Consc Studies 3:330-350

VARELA FJ (1997a) Patterns of Life: Intertwining identity and cognition. Brain Cognition 34:72-87

VARELA FJ (1997b) The Naturalization of Phenomenology as the Transcendence of Nature: searching for generative mutual constraints. Alter: Revue de Phénoménologie 5:355-385 (Paris)

VARELA FJ (1997c) Metaphor to mechanism: Natural to disciplined. J Consc Studies 4:344-346

VARELA FJ (1999a) The specious present: the neurophenomenology of time consciousness. In: PETITOT J, VARELA FJ, PACHOUD B, ROY JM (eds) Naturalizing Phenomenology. Stanford, CA: Stanford University Press. pp:266-314

VARELA FJ (1999b) Steps to a science of Interbeing: unfolding the Dharma implicit in modern cognitive science. In: BACHELOR S, CLAXTON G WATSON G (eds) The Psychology of Awakening: Buddhism, Science and Our Day to Day Lives. New York: Rider/ Random House. pp:71-89

VARELA FJ (1999c) Dasein's brain: phenomenology meets cognitive science. In: AERTS D (ed) Einstein meets Magritte: the white book. Dordrecht: Kluwer Academic Publishers. pp:185-197

VARELA FJ (1999d) Le Cerveau et la Pensee: La revolution des Sciences Cognitives. Paris: Editions Sciences Humaines. pp: 327-335

VARELA FJ, COHEN A (1989) Le corps evocateur: une relecture de l'immunité. Nouvelle Revue de Psychanalyse 40: 193-213

VARELA FJ, DEPRAZ N (2000) At the source of time: valence and the constitutional dynamics of affect. In: Ipseity and Alterity. Arob@se: An electronic journal.

VARELA FJ, FRENK S (1987) The organ of form: Towards a biological theory of shape. J Soc Biol Struct 10:7383

VARELA FJ, GOGUEN J (1977) The arithmetic of closure. In: TRAPPL R (ed) Progress in Cybernetics and Systems Research. Vol. 3. New York: Wiley Hemisphere. pp:48-63

VARELA FJ, MATURANA H (1973) Mechanism and biological explanation. Phil Sci 39:378-382

VARELA FJ , SHEAR J (1999a) First-person methodologies: why, when and how. J Consc Studies 6(2-3): 1-14

VARELA FJ, SHEAR J (1999b) (eds) The View from Within: First-Person Methodologies in the Study of Consciousness. Special Issue. J of Consciousness Studies, 6 (2-3)

VARELA FJ, MATURANA H, URIBE R (1974) Autopoiesis: The organization of living systems, its characterization and a model. Biosyst 5:187-196

VARELA F, TORO A, JOHN ER, SCHWARTZ E (1981) Perceptual framing and cortical alpha rhythms. Neuropsychologia 19:675-686 
VARELA FJ, THOMPSON E, ROSCH E (1991) The Embodied Mind: Cognitive science and human experience. Cambridge, MA: MIT Press

VARELA FJ, LACHAUX JP, RODRIGUEZ E, MARTINERIE J (2001) The brainweb: phase synchronization and large-scale integration. Nat Rev Neurosci 2(4):229-39 Rev
VAZ N, VARELA FJ (1978) Self and non-sense: An organism- centered approach to immunology. Medical Hypothesis 4:231-267

WEBER A, VARELA FJ (2002), Life after Kant: Natural purposes and autopoietic foundations of biological individuality. Pheno Cogn Sci 1(2):97-125

ZEMAN A (2001) Consciousness. Brain 124(7):1263-89 Rev 